\title{
Ultrasound Assessment of Fetal Neurobehavior in High-risk Pregnancies
}

Radu Vladareanu, Daniela Lebit, Simona Constantinescu

\begin{abstract}
Objectives: Assessment of the fetal behavior in normal and high-risk pregnancy during second and third trimesters.
\end{abstract}

\begin{abstract}
Materials and methods: The study group included 61 healthy pregnant women and 135 pregnant women with high-risk pregnancy between 24 and 38 weeks of gestation for a period of 3 years (January 2009-May 2011). After 4D ultrasound examination we applied antenatal neurological score KANET 1. Score is considered normal between 14 and 20, borderline between 6 and 13 and abnormal between 0 and 5 .
\end{abstract}

Results: The Kurjak antenatal neurological test (KANET) scores have significant differences, when applied on the two groups of pregnant women. Most fetuses who obtained normal KANET score were found in normal pregnancies, those who obtained borderline score were fetuses with intrauterine growth restriction (IUGR) with increased resistance index (RI) of middle cerebral artery (ACM) and the most fetuses with abnormal KANET score came from pregnancies complicated by threatened preterm delivery with PPROM.

Conclusion: Dynamic evaluation of fetal behavior reflects directly the processes of maturation and development of the central nervous system. This can make the difference between normal and abnormal brain development and may be used for early diagnosis of neurological disorders that become manifest in perinatal and postnatal periods.

Keywords: Fetal behavior, KANET score, High-risk pregnancy, Ultrasound 4D.

How to cite this article: Vladareanu R, Lebit D, Constantinescu S. Ultrasound Assessment of Fetal Neurobehavior in High-risk Pregnancies. Donald School J Ultrasound Obstet Gynecol 2012;6(2):132-147.

\section{Source of support: Nil}

Conflict of interest: None declared

\section{INTRODUCTION}

Fetal behavior represents activities of the fetus documented by means of ultrasound examination. ${ }^{3-6}$ The introduction of $4 \mathrm{D}$ ultrasound in obstetrics practice allowed following the fetal movements and facial expressions. Noticing abnormal behavior can be useful in the early detection of neurological disorders, ${ }^{7}$ the most serious of which being cerebral palsy.

Fetal behavior is in strong connection with the development and maturation process of the central nervous system. ${ }^{4,8}$ Based on this idea, a neurological score was developed, based on quantitative and qualitative antenatal assessment of some fetal parameters (antenatal neurological score KANET. ${ }^{9}$ 4D ultrasound enables simultaneously three-dimensional following of head, body and limbs movements in real time and offers a practical means for assessment of both the brain function and structure. ${ }^{10}$ In the early 2nd trimester, 4D US provides simultaneous visualization of all four extremities and enables depiction of isolated arm movements and their direction. ${ }^{11}$

Simultaneous imaging of complex facial movements was not possible using real-time 2D sonography. ${ }^{12}$ Therefore, this new technology allows the appearance and duration of each facial movement and expression to be determined and measured. ${ }^{13}$ With 4D US, it is now feasible to study a full range of facial expressions, including smiling, crying, scowling, mouthing and eyelid movements. ${ }^{14}$

During 40 weeks of gestation, the repertoire of fetal activities constantly expands, correlating precisely with structural development of the central nervous system (CNS). ${ }^{15}$ Major developmental events, such as the establishment of neural connections in the different regions of the brain, are accompanied by the occurrence of new patterns of fetal activity or with the transformation of the existing patterns. ${ }^{15}$

Understanding the relationship between fetal behavior and brain developmental processes in different periods of gestation makes it possible to distinguish between normal and abnormal CNS development and early diagnosis of various structural and functional abnormalities. ${ }^{3,7,16}$

\section{AIM}

The aim of the research was to distinguish between and assess normal and abnormal fetal behavior and to illustrate how the assessment of fetal behavior can facilitate early diagnose of neurological diseases.

The goal of $4 \mathrm{D}$ ultrasound procedure is to discover whether the quality of fetal movements and facial expressions can also be used to diagnose prenatal neurological disorders. ${ }^{12}$

\section{FETAL BEHAVIOR AS POSSIBLE SCREENING METHOD OF NEUROLOGICAL DISEASES}

According to the recent studies, many neurological disorders, such as minimal cerebral dysfunction, schizophrenia, epilepsy or autism could result at least in part from prenatal neurodevelopment problems. ${ }^{17,18}$ Clinical and epidemiological studies have shown that even cerebral 
Ultrasound Assessment of Fetal Neurobehavior in High-risk Pregnancies

palsy (CP) most frequently results from prenatal rather than postnatal causes. ${ }^{19,20}$

The purpose of early diagnosis of CP could be important from the point of view of the infant, the mother, the family and the gynecologists who are often held responsible for brain damage in neonates. ${ }^{2,3}$

The fetal behavior may be influenced by a number of external factors, such as cigarettes smoking, ${ }^{21}$ corticosteroids for fetal lung maturation ${ }^{22}$ which can decrease the number of spontaneous fetal movements. ${ }^{3,23}$ It has been known that qualitative alteration of general movements can be observed in preterm and term newborns cerebral injury. ${ }^{24,25}$ Their movements can be monotone, lack in complexity, are repetitive, chaotic and involve muscle contraction. $^{3,25}$ The general movements are diagnose as normal if the movements are complex, fluent, including neck, trunk and limb movements, and wax and wane in their intensity. ${ }^{9,25}$ Qualitative alterations in fetal movements have been observed in several conditions, such as diabetes mellitus, intrauterine growth restriction, hypertension, threatened preterm delivery with preterm premature rupture of membranes (PPROM).

The quality of fetal movement patterns is altered in fetuses suffering from intrauterine growth restriction. The movements become slower, monotonous, resembling cramps, and their variability in the strength and amplitude is reduced. These changes could indicate the existence of brain lesions in growth restricted and possibly hypoxic fetuses. ${ }^{26}$ Fetuses with IUGR show changes in amplitude and complexity of fetal movements which do not appear due to oligohydramnios. ${ }^{9}$ In cases of premature rupture of fetal membranes and subsequently reduced volume of amniotic fluid, movements occur less frequently, but their complexity resembles that of movements performed in the normal volume of amniotic fluid. ${ }^{26}$ Abnormal movements are monotone, lack in complexity, are repetitive, chaotic and involve muscle contraction. These changes might indicate the existence of brain lesions in grow-restricted and possibly hypoxic fetuses. ${ }^{24}$

\section{MATERIALS AND METHODS}

This is a prospective longitudinal study conducted in the Department of Obstetrics and Gynecology in Elias Hospital from Bucharest over a 3 years period (January 2009-May 2011). The study included two groups of pregnant women. The first group included 135 women with maternal or fetal high-risk pregnancies and the second group included 61 women with normal pregnancies (control group).

\section{Inclusion Criteria}

1. Pregnant women with maternal or fetal high-risk pregnancies (Table 1).
Table 1: Inclusion criteria of high-risk pregnancies

\begin{tabular}{ll}
\hline Family history & $\begin{array}{l}\text { Previous child with cerebral palsy } \\
\text { Diabetes mellitus type II, } \\
\text { hypertension } \\
\text { Intrauterine growth restriction } \\
\text { (IUGR), polyhydramnios } \\
\text { Fetal condition }\end{array}$ \\
$\begin{array}{l}\text { Gestational diabetes, Rh } \\
\text { isoimmunization, threatened } \\
\text { preterm delivery }\end{array}$ \\
\hline
\end{tabular}

2. Singleton pregnancies assessed normal after 2D ultrasound examination.

We excluded from the study fetuses with chromosomal abnormalities, smoking and alcohol consuming mothers. Both groups were examined by 4D ultrasound using Voluson 730 with 5 MHz transabdominal transducer. Each examination lasted between 15 and 30 minutes. All patients signed an informed consent to be included in the study. We evaluated quantitatively and qualitatively 10 fetal parameters and graded them from 0 to 2 . By adding up these figures, we calculated KANET scores for each lot and subgroup of diseases.

In this study, we compared:

- KANET scores of low and high-risk group fetuses

- Distribution of fetuses from each KANET subgroup

- Significance of individual parameters of KANET score

- Pattern of movements in threatened preterm delivery subgroup and in pregnancies complicated by IUGR vs control group.

In order to calculate the KANET score, we evaluated the following parameters in the two groups of pregnant women: Isolated head anteflexion, overlapping cranial sutures and head circumference, isolated eye movements, facial expressions and mouthing (grimace and tongue expulsion), isolated hand movements, isolated leg movements, hand to face movements, finger movements and thumb position (neurologic thumb) ${ }^{2}$ and qualitative assessment of general movements. There is a three-point scale for isolated head anteflexion, isolated hand, leg, hand to face and finger movements, while for the assessment of cranial sutures, isolated eye blinking, facial alterations and mouth opening were scored with numbers from 0 to 2 . Except head anteflexion and isolated eye movements, all parameters included in the KANET score calculation showed statistically significant differences in the two groups.

\section{Examined Parameters ${ }^{1,3,12}$}

1. Head anteflexion

- Normal-most often are at slow speed, not associated with general movements, sometimes can be sudden and rapid ${ }^{1}$

- Abnormal-abrupt or rigid movements 
2. Cranial sutures and cranial circumference

- Normal-nonoverlapping cranial bones, the sutures are visible

- Abnormal-overlapping cranial bones, head circumference $<2$ SD than normal

3. (i) Isolated eye movements

- Normal-opening and closing movements of the eyes are smooth, without muscle contractions; these movements can be voluntary or involuntary

- Abnormal-very rare or rapid movements

(ii) Facial expressions (grimacing or tongue expulsion)

- Normal-facial expressions (smile, frown or tongue expulsion) are visible

- Abnormal-absent or very rare facial movements. 'Face looks just like a picture'

(iii) Mouth movements (yawning or mouthing)

- Normal-fetus closes/opens mouth with displacements of tongue and/or larynx. The fetus swallows amniotic fluid. Yawning movements are commonly associated with head anteflexion and elevation of the arms

- Abnormal-absent or rare movements of the tongue and yawning

4. Isolated hand movements

- Normal-rapid or slow movements that may involve flexion, extension, adduction, abduction, external and internal rotation of the hands without involving other parts of the body

- Abnormal-monotonous, less complex or rigid movements

5. Isolated leg movements

- Normal-rapid or slow movements that may involve flexion, extension, adduction, abduction, external and internal rotation of the legs

- Abnormal-lack of complexity or rigid movements with muscle contractions

6. Hand to face movements

- Normal-complex movements, the hand touches different parts of the face. It is frequently associated with finger movements
- Abnormal_rigid and chaotic movements, without a target

\section{Finger movements and thumb position}

- Normal-clenching and unclenching of the fist. Most of the time, normal position of the thumb is outside the fist

- Abnormal-lack of finger movement, 'neurological sign of the thumb'

8. Gestalt perception of general movements

- Normal-smooth, complex movements involving head, trunk and limbs that increase and decrease in amplitude

- Abnormal-monotonous movements with lack of complexity, repetitive or chaotic with muscle contraction.

Interpretation of KANET scores are as follows:

- Normal-between 14 and 20

- Borderline-between 6 and 13

- Abnormal-between 0 and 5.

\section{RESULTS}

We found a statistically significant difference $(p<0.001)$ of the KANET score values in the two groups of pregnant women by applying Mann-Whitney U-test (Table 2, Fig. 1).

In Table 3, we presented the distribution of fetuses as normal, borderline and abnormal after KANET scoring. We used Chi-square test and obtained a statistically significant difference between the two groups of fetuses of pregnant women (Table 3, Fig. 2).

Using Kruskal-Wallis and Conover-Inman tests, we compared KANET scores of each subgroup of high-risk pregnancies to the control group (low-risk pregnancies). We found statistically significant differences in pregnancies complicated by threatened preterm delivery, intrauterine growth restriction, diabetes, hypertension above 160/ $100 \mathrm{~mm} \mathrm{Hg}$, Rhesus isoimmunization with fetal hydrops and polyhydramnios (Table 4).

Table 2: Comparison of KANET scores in low- and high-risk pregnancies

\begin{tabular}{lccccc}
\hline Group & Number & $\begin{array}{l}\text { KANET } \\
\text { Mean }\end{array}$ & $\begin{array}{c}\text { KANET } \\
\text { Min-max }\end{array}$ & $\begin{array}{c}\text { KANET } \\
\text { SD }\end{array}$ & $\begin{array}{c}\text { KANET } \\
\text { Median }\end{array}$ \\
\hline Low risk & 61 & 17.44 & $5-20$ & 2.47 & 18 \\
High risk & 135 & 15.53 & $3-20$ & 3.55 & $17-19$ \\
\hline
\end{tabular}

Table 3: Distribution of fetuses after KANET scoring $(p=0.0353)$

\begin{tabular}{|c|c|c|c|c|c|c|c|}
\hline \multirow[t]{2}{*}{ Group } & \multirow[t]{2}{*}{ Total } & \multicolumn{2}{|c|}{ Normal } & \multicolumn{2}{|c|}{ Borderline } & \multicolumn{2}{|c|}{ Abnormal } \\
\hline & & Number & Percentage & Number & Percentage & Number & Percentage \\
\hline Low risk & 61 & 57 & 93.4 & 3 & 4.9 & 1 & 1.6 \\
\hline High risk & 135 & 106 & 78.5 & 22 & 16.3 & 7 & 5.2 \\
\hline
\end{tabular}


Ultrasound Assessment of Fetal Neurobehavior in High-risk Pregnancies

\begin{tabular}{|c|c|c|c|c|c|}
\hline Group & Subgroup & Number & $\begin{array}{l}\text { KANET score } \\
\text { Mean }\end{array}$ & $\begin{array}{l}\text { KANET score } \\
\text { SD }\end{array}$ & $p$-value \\
\hline Low risk & & 61 & 17.44 & 2.47 & \\
\hline $\begin{array}{l}\text { Threatened preterm } \\
\text { delivery }\end{array}$ & $\begin{array}{l}\text { With PPROM } \\
\text { Without PPROM }\end{array}$ & $\begin{array}{r}8 \\
21\end{array}$ & $\begin{array}{l}10.00 \\
15.81\end{array}$ & $\begin{array}{l}4.99 \\
3.30\end{array}$ & $\begin{array}{r}<0.001 \\
0.008\end{array}$ \\
\hline $\begin{array}{l}\text { Previous child with } \\
\text { cerebral palsy }\end{array}$ & & 2 & 18.00 & 0.00 & 0.761 (NS) \\
\hline Diabetes & $\begin{array}{l}\text { Gestational } \\
\text { Type II }\end{array}$ & $\begin{array}{l}6 \\
3\end{array}$ & $\begin{array}{l}16.67 \\
15.33\end{array}$ & $\begin{array}{l}2.73 \\
2.52\end{array}$ & $\begin{array}{l}0.405 \text { (NS) } \\
0.062 \text { (NS) }\end{array}$ \\
\hline Hypertension & $\begin{array}{l}<160 / 100 \mathrm{~mm} \mathrm{Hg} \\
>160 / 100 \mathrm{~mm} \mathrm{Hg}\end{array}$ & $\begin{array}{r}26 \\
9\end{array}$ & $\begin{array}{l}16.58 \\
12.11\end{array}$ & $\begin{array}{l}2.98 \\
3.89\end{array}$ & $\begin{array}{l}0.07 \text { (NS) } \\
<0.001\end{array}$ \\
\hline $\begin{array}{l}\text { Intrauterine growth } \\
\text { restriction (IUGR) }\end{array}$ & $\begin{array}{l}\text { With MCA RI changes } \\
\text { Normal MCA RI }\end{array}$ & $\begin{array}{r}4 \\
26\end{array}$ & $\begin{array}{l}11.25 \\
16.65\end{array}$ & $\begin{array}{l}4.65 \\
1.65\end{array}$ & $\begin{array}{r}<0.001 \\
0.011\end{array}$ \\
\hline $\mathrm{Rh}$ isoimmunization & $\begin{array}{l}\text { With hydrops fetalis } \\
\text { Without hydrops fetalis }\end{array}$ & $\begin{array}{r}2 \\
25\end{array}$ & $\begin{array}{r}8.50 \\
16.96\end{array}$ & $\begin{array}{l}4.95 \\
1.77\end{array}$ & $\begin{array}{l}0.002 \\
0.121 \text { (NS) }\end{array}$ \\
\hline Polyhydramnios & & 3 & 14.67 & 2.52 & 0.019 \\
\hline
\end{tabular}

NS: Not significant

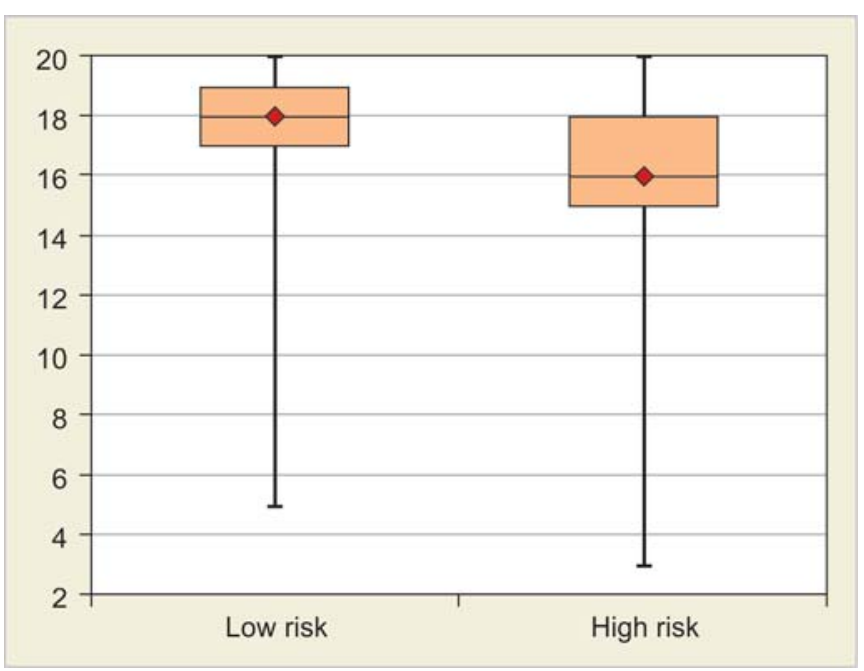

Fig. 1: Comparison of KANET scores in low- and high-risk pregnancies

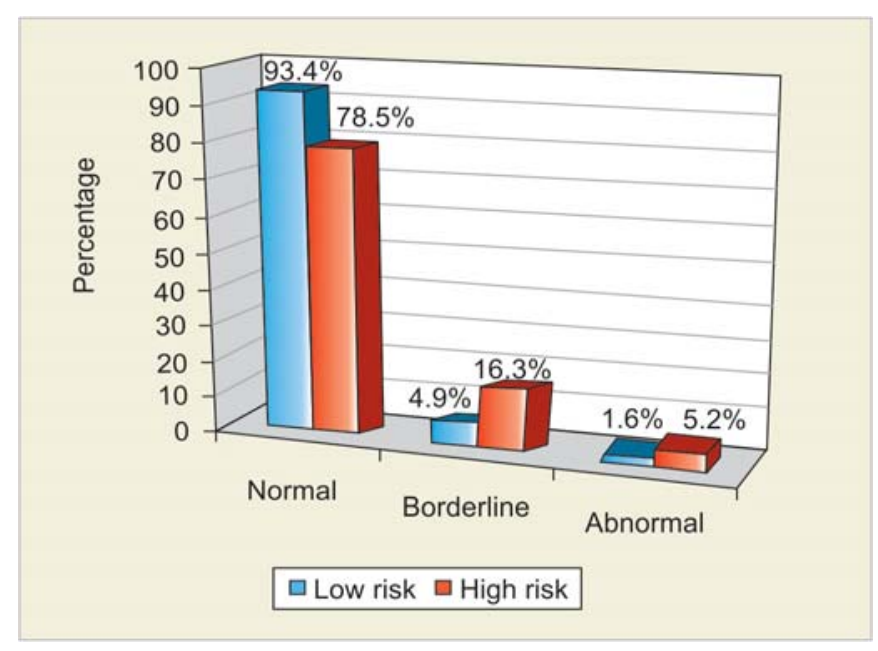

Fig. 2: Distribution of fetuses after KANET scoring $(p=0.0353)$

Pregnancies complicated by hypertension below 160/100 mm Hg, Rh isoimmunization without fetal hydrops, pregnancies complicated by cerebral palsy and pregnancies with a history of diabetes were not statistically significant.
The results obtained on the subtypes of diseases were compared using the Chi-square test: Hypertension above 160/100 mm Hg vs hypertension below 160/100 mm Hg, gestational diabetes $v$ s type II diabetes, threatened preterm delivery with PPROM vs without PPROM, IUGR with MCA RI changes vs normal MCA RI and Rh isoimmunization with hydrops fetalis vs Rh isoimmunization without hydrops fetalis (Table 5).

In the high-risk pregnancy group, we found the following distribution: The highest percentage of abnormal KANET score was in threatened preterm delivery with PPROM (25\%). The highest incidence of fetuses with borderline KANET score was in IUGR with MCA RI changes (50\%) and threatened preterm delivery with PPROM (50\%). Most fetuses with normal KANET score came from pregnancies complicated by Rh isoimmunization without hydrops fetalis (96\%) and pregnancies complicated by hypertension below 160/100 mm Hg (92.3\%). The KANET scores for fetuses in different subgroups of highrisk pregnancies are shown in the Table 5.

In Table 6, we compared each parameter used in KANET score calculation on the two groups and found statistically significant values for the following parameters: Cranial sutures, facial expressions, mouthing, isolated arm movements, isolated leg movements, hand to face movements, finger movements and the gestalt perception of the general movements. Head anteflexion and isolated eye blinking were not statistically significant.

Further, we analyzed the incidence of the fetal movements frequency in threatened preterm delivery and in pregnancies complicated by IUGR vs control group between 28 and 36 weeks of gestation.

The figures illustrate a comparison between normal and threatened preterm delivery fetuses by examining facial expressions and fetal movements at the end of the 2nd 
Table 5: Distribution of fetuses from the subgroups of high-risk pregnancies according to the KANET scores

\begin{tabular}{|c|c|c|c|c|c|c|c|c|}
\hline \multirow[t]{2}{*}{ Subgroup } & \multirow[t]{2}{*}{ Total } & \multicolumn{2}{|c|}{ Normal } & \multicolumn{2}{|c|}{ Borderline } & \multicolumn{2}{|c|}{ Abnormal } & \multirow[t]{2}{*}{$p$-value } \\
\hline & & Number & Percentage & Number & Percentage & Number & Percentage & \\
\hline $\begin{array}{l}\text { Threatened } \\
\text { preterm delivery }\end{array}$ & 29 & 18 & 62.1 & 8 & 27.6 & 3 & 10.3 & 0.034 \\
\hline With PPROM & 8 & 2 & 25.0 & 4 & 50.0 & 2 & 25.0 & \\
\hline Without PPROM & 21 & 16 & 76.2 & 4 & 19.0 & 1 & 4.8 & \\
\hline Diabetes & 9 & 7 & 77.8 & 2 & 22.2 & 0 & 0.0 & 0.852 \\
\hline Gestational & 6 & 5 & 83.3 & 1 & 16.7 & 0 & 0.0 & (NS) \\
\hline Type II & 3 & 2 & 66.7 & 1 & 33.3 & 0 & 0.0 & \\
\hline Hypertension & 35 & 27 & 77.1 & 6 & 17.1 & 2 & 5.7 & $<0.001$ \\
\hline$<160 / 100 \mathrm{~mm} \mathrm{Hg}$ & 26 & 24 & 92.3 & 1 & 3.8 & 1 & 3.8 & \\
\hline$>160 / 100 \mathrm{~mm} \mathrm{Hg}$ & 9 & 3 & 33.3 & 5 & 55.6 & 1 & 11.1 & \\
\hline $\begin{array}{l}\text { Intrauterine growth } \\
\text { restriction (IUGR) }\end{array}$ & 30 & 26 & 86.7 & 3 & 10.0 & 1 & 3.3 & $<0.001$ \\
\hline With MCA RI changes & 4 & 1 & 25.0 & 2 & 50.0 & 1 & 25.0 & \\
\hline Normal MCA RI & 26 & 25 & 96.2 & 1 & 3.8 & 0 & 0.0 & \\
\hline $\mathrm{Rh}$ isoimmunization & 27 & 24 & 88.9 & 2 & 7.4 & 1 & 3.7 & $<0.001$ \\
\hline With hydrops fetalis & 2 & 0 & 0.0 & 1 & 50.0 & 1 & 50.0 & \\
\hline Without hydrops fetalis & 25 & 24 & 96.0 & 1 & 4.0 & 0 & 0.0 & \\
\hline
\end{tabular}

Table 6: KANET parameters comparison between fetuses in low-risk and high-risk pregnancies

\begin{tabular}{|c|c|c|c|c|c|}
\hline \multirow[t]{2}{*}{ KANET parameter } & \multirow[t]{2}{*}{ Group } & \multicolumn{3}{|c|}{ KANET score } & \multirow[t]{2}{*}{$p$-value } \\
\hline & & 0 & 1 & 2 & \\
\hline \multirow[t]{2}{*}{ Head anteflexion } & $\mathrm{HR}$ & 9 & 47 & 79 & 0.891 (NS) \\
\hline & LR & 3 & 22 & 36 & \\
\hline \multirow[t]{2}{*}{ Cranial sutures } & HR & 3 & 19 & 113 & 0.034 \\
\hline & LR & 0 & 2 & 59 & \\
\hline \multirow[t]{2}{*}{ Isolated eye blinking } & HR & 6 & 58 & 71 & 0.883 (NS) \\
\hline & LR & 2 & 28 & 31 & \\
\hline \multirow[t]{2}{*}{ Facial expressions } & $\mathrm{HR}$ & 16 & 63 & 56 & 0.046 \\
\hline & LR & 2 & 24 & 35 & \\
\hline \multirow[t]{2}{*}{ Mouthing } & $\mathrm{HR}$ & 16 & 77 & 42 & $<0.001$ \\
\hline & LR & 1 & 23 & 37 & \\
\hline \multirow[t]{2}{*}{ Isolated hand movements } & $\mathrm{HR}$ & 4 & 27 & 104 & 0.044 \\
\hline & LR & 1 & 4 & 56 & \\
\hline \multirow[t]{2}{*}{ Isolated leg movements } & $\mathrm{HR}$ & 3 & 41 & 91 & 0.007 \\
\hline & LR & 0 & 7 & 54 & \\
\hline \multirow[t]{2}{*}{ Hand to face movements } & $\mathrm{HR}$ & 9 & 55 & 71 & 0.043 \\
\hline & LR & 1 & 17 & 43 & \\
\hline \multirow[t]{2}{*}{ Finger movements } & HR & 6 & 29 & 100 & 0.002 \\
\hline & LR & 1 & 2 & 58 & \\
\hline \multirow[t]{2}{*}{ Gestalt perception } & $\mathrm{HR}$ & 9 & 25 & 101 & 0.009 \\
\hline & LR & 1 & 3 & 57 & \\
\hline
\end{tabular}

trimester and the ones in the 3rd trimester. The median value of all movement patterns in the normal fetuses differed from that in fetuses with threatened preterm delivery. Statistical evaluation (rank-sum test) revealed statistically significant differences in isolated eye blinking, head movements, yawning, grimacing, swallowing, mouthing, hand to face, hand to eye, hand to mouth and hand to head movements ( $\mathrm{p}<0.05)$ (Figs 3 to 26).

Tongue expulsion and hand to ear movements have not displayed statistical significance (Figs 27 to 30).

Linear and polynomial regressions showed that all head and hand movements, isolated eye blinking, mouthing, swallowing had a negative slope between frequency and gestational age. Tongue expulsion, grimacing and yawning displayed a constant incidence in this period.

The statistical analysis of the incidence of fetal movements and facial expressions in normal and the pregnancies complicated by IUGR revealed statistically significant changes in isolated eye blinking, head movements, yawning, grimacing, swallowing, mouthing, hand to face, hand to eye, hand to mouth and hand to head movements, tongue expulsion and hand to ear movements $(p<0.05)$ (Figs 31 to 58). 


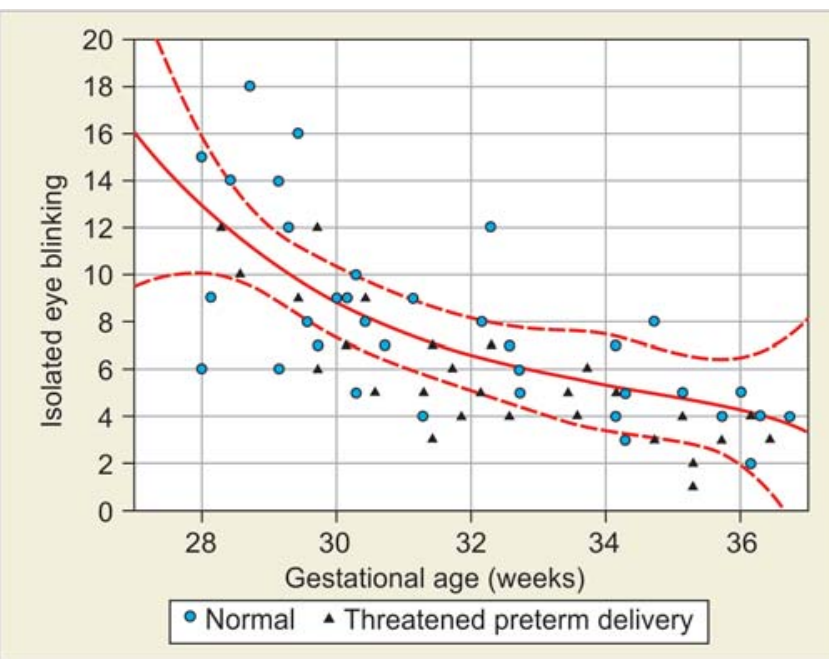

Fig. 3: Scatterplot and polynomial regression of the frequency of isolated eye blinking

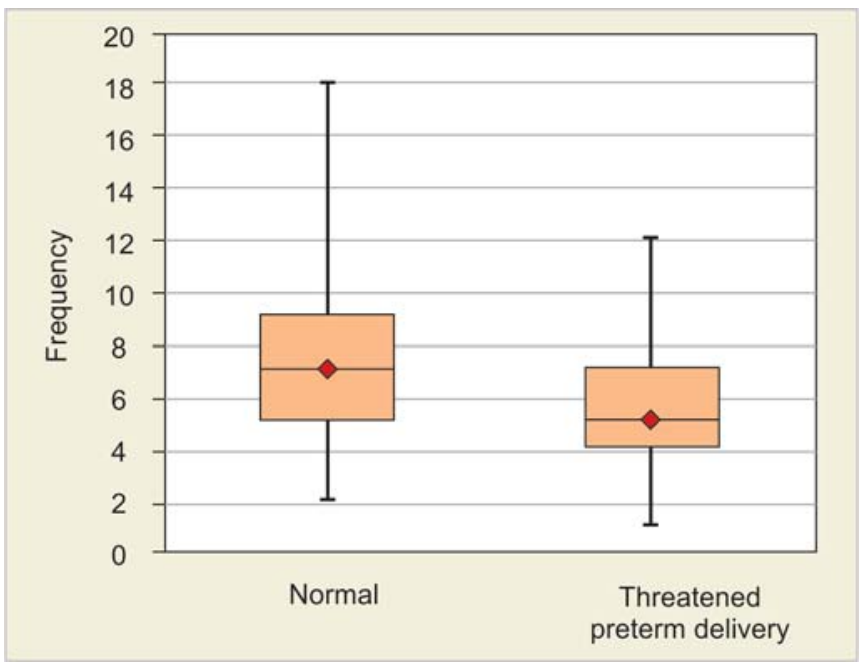

Fig. 4: Comparison of the frequency of isolated eye blinking between normal and threatened preterm delivery $(p=0.013)$

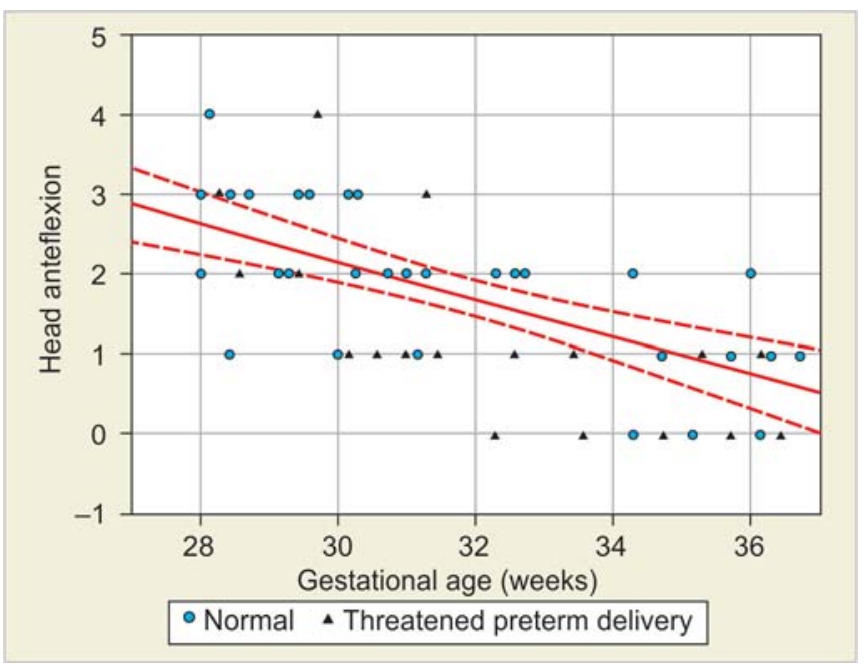

Fig. 5: Scatterplot and linear regression of the frequency of head anteflexion

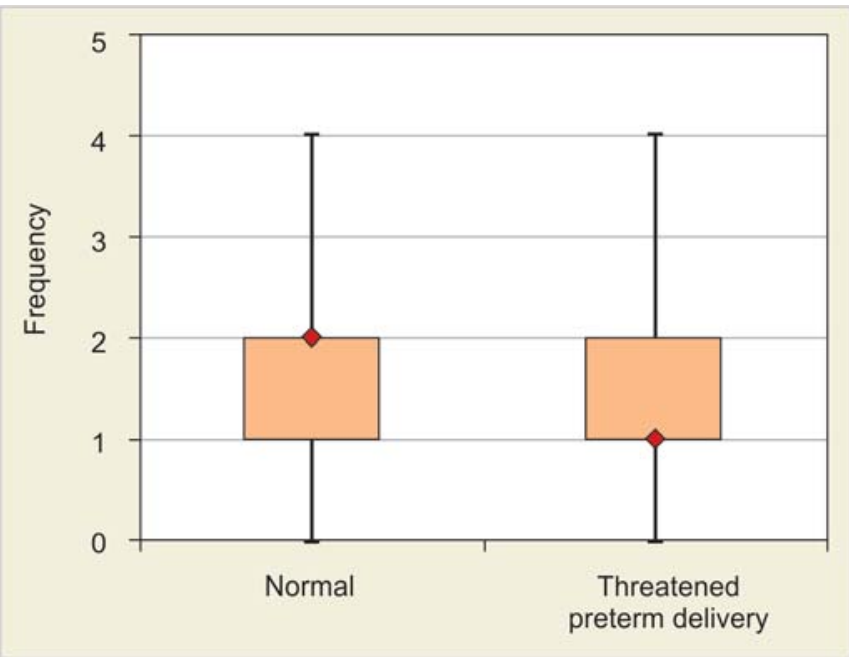

Fig. 6: Comparison of the frequency of head anteflexion between normal and threatened preterm delivery $(p=0.019)$

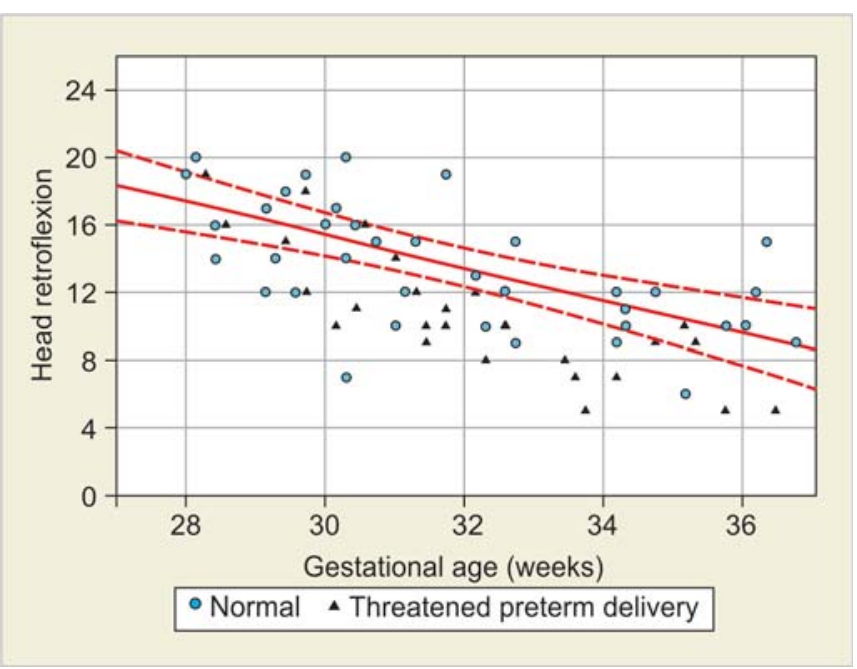

Fig. 7: Scatterplot and linear regression of the frequency of head retroflexion

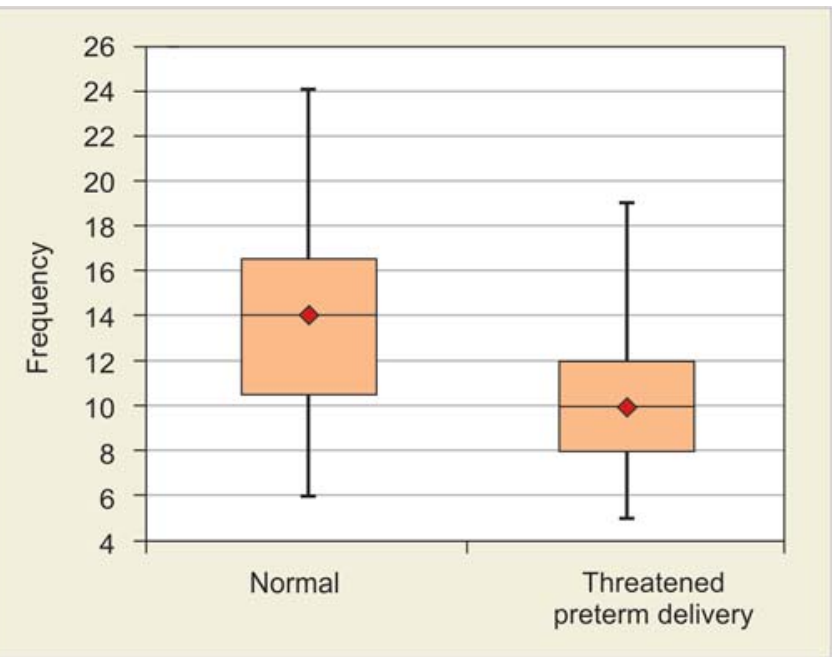

Fig. 8: Comparison of the frequency of head retroflexion between normal and threatened preterm delivery $(p=0.001)$ 


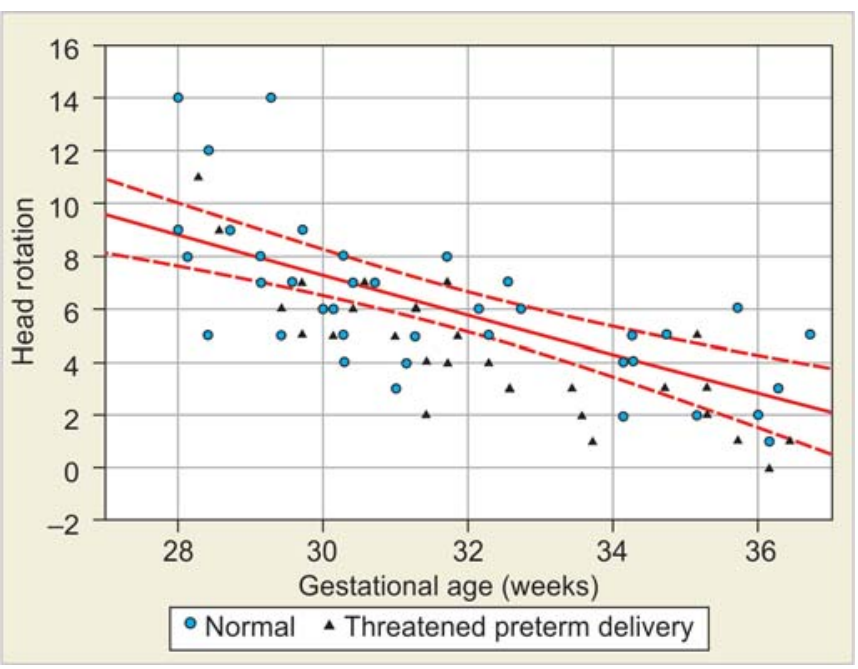

Fig. 9: Scatterplot and linear regression of the frequency of head rotation

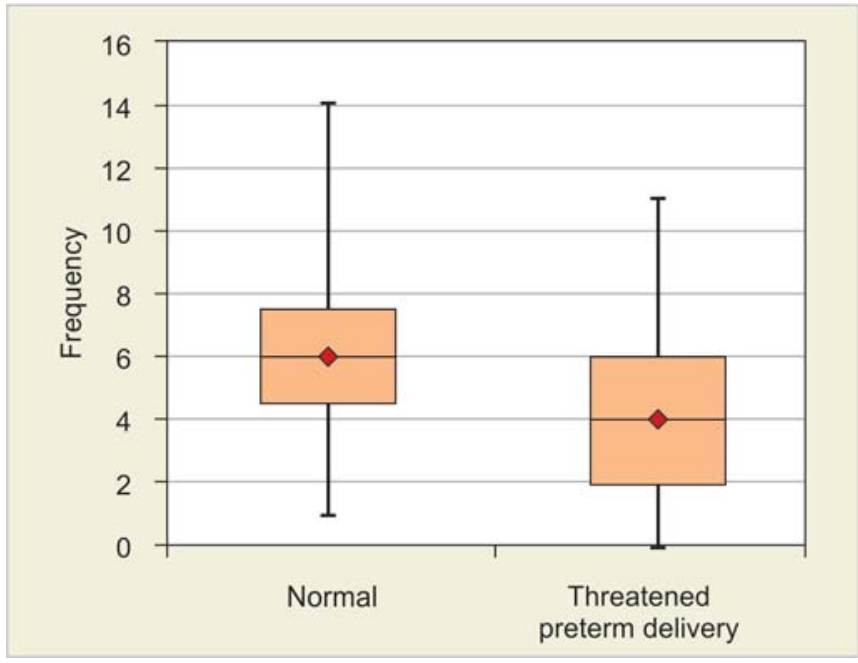

Fig. 10: Comparison of the frequency of head rotation between normal and threatened preterm delivery $(p=0.01)$

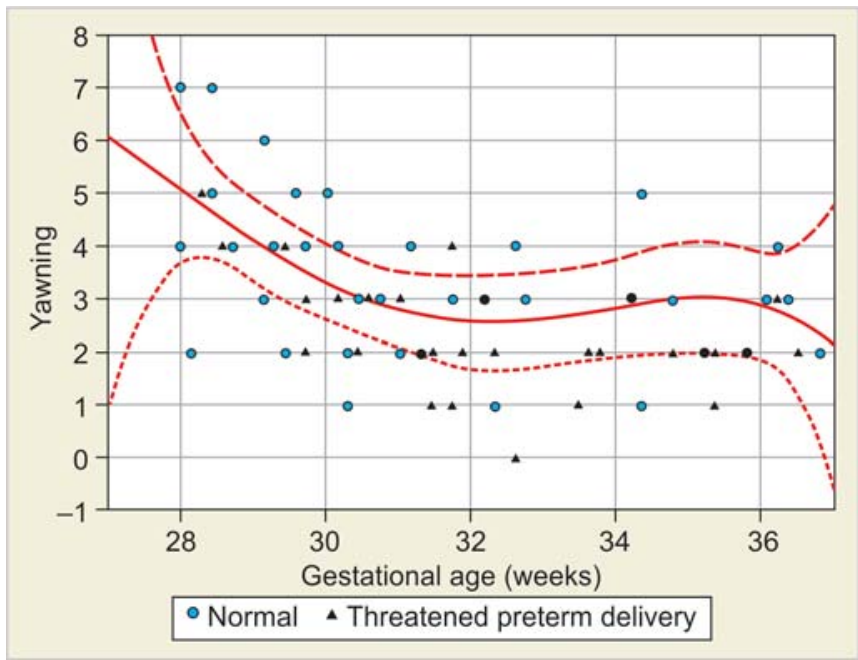

Fig. 11: Scatterplot and polynomial regression of the frequency of yawning

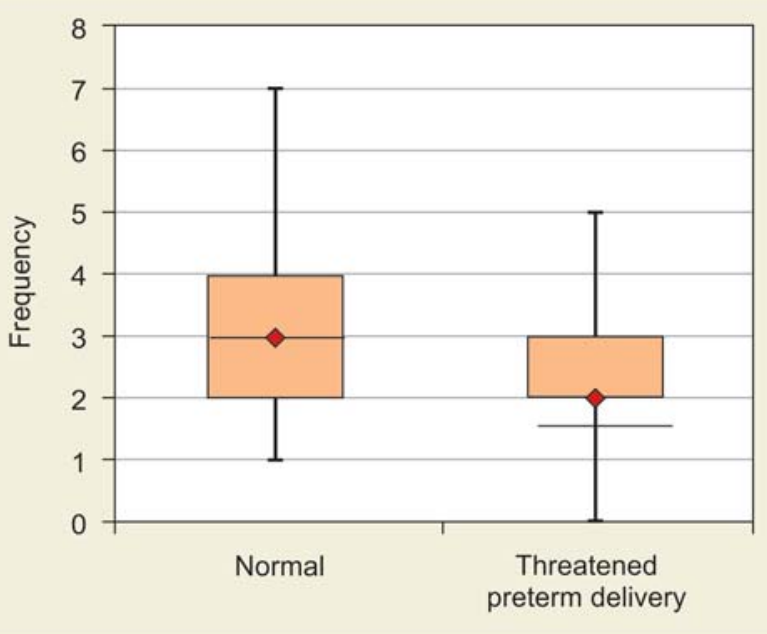

Fig. 12: Comparison of the frequency of yawning between normal and threatened preterm delivery $(p=0.005)$

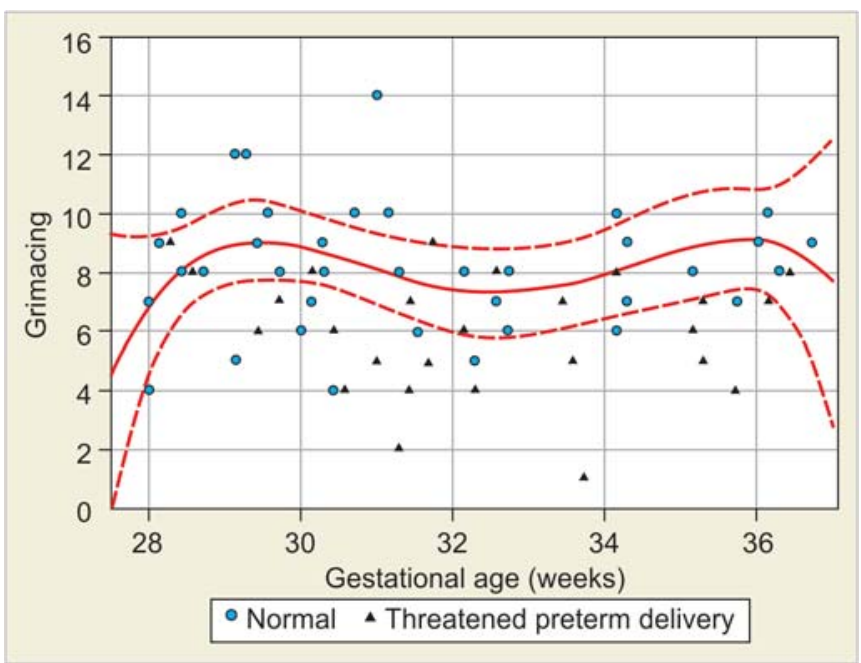

Fig. 13: Scatterplot and polynomial regression of the frequency of grimacing

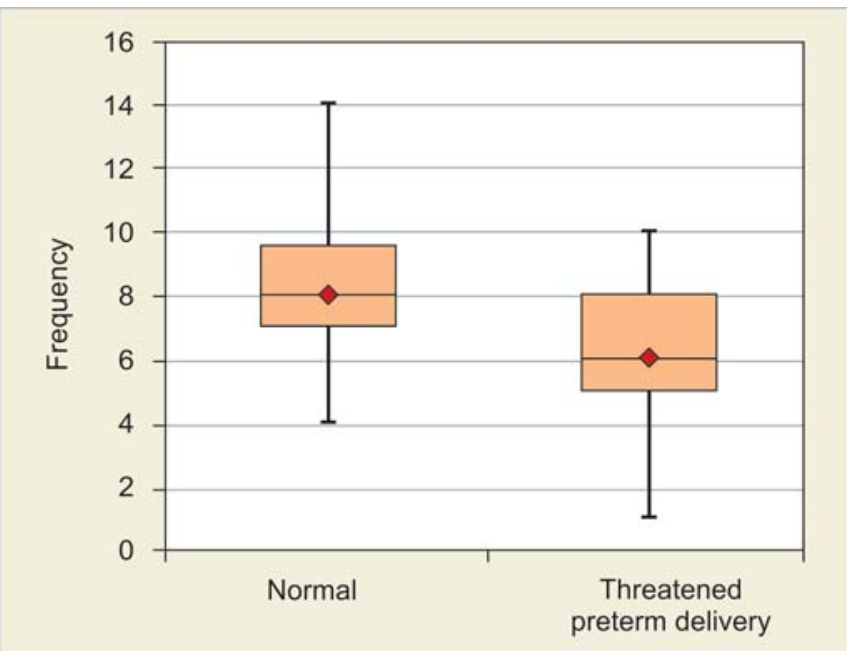

Fig. 14: Comparison of the frequency of grimacing between normal and threatened preterm delivery $(p<0.001)$ 


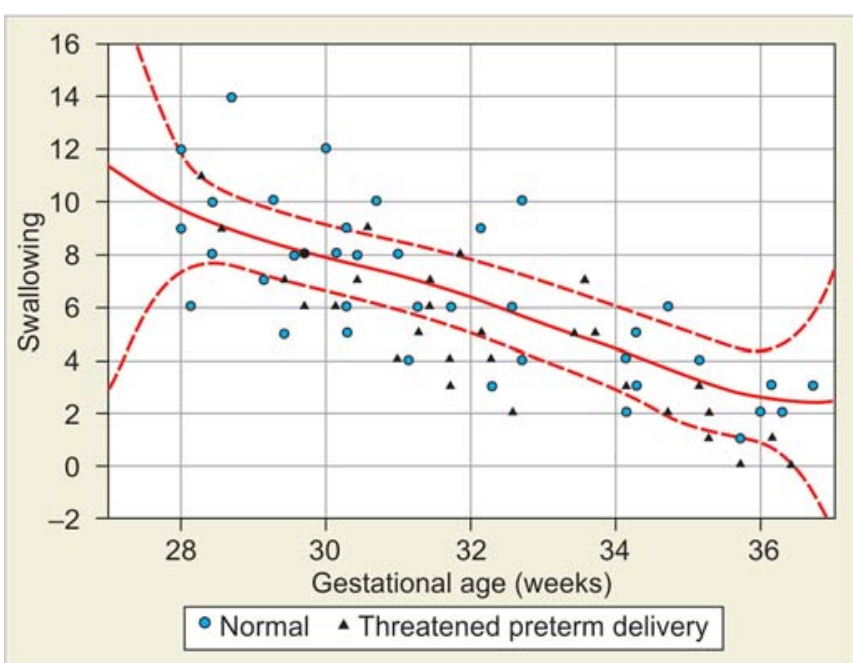

Fig. 15: Scatterplot and polynomial regression of the frequency of swallowing

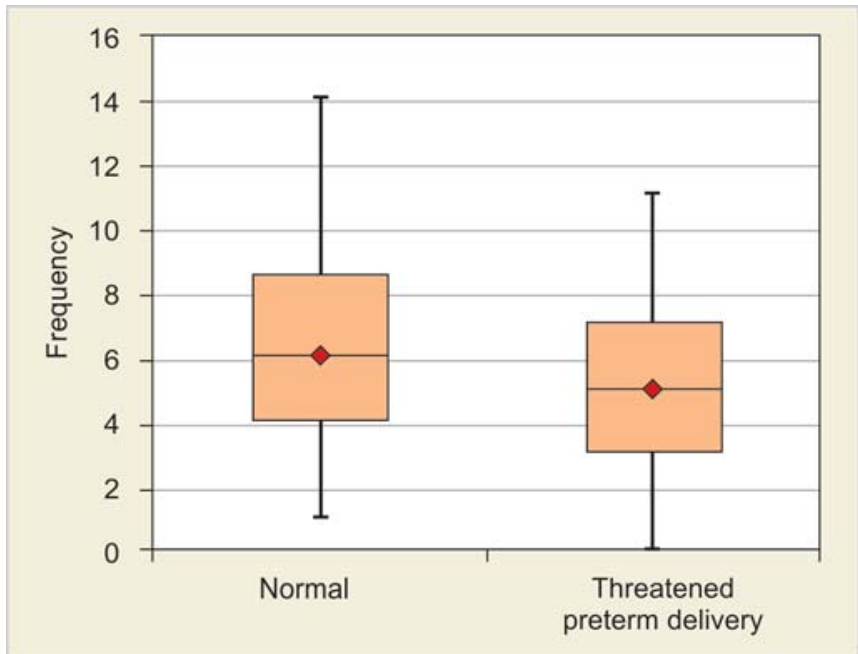

Fig. 16: Comparison of the frequency of swallowing between normal and threatened preterm delivery $(p=0.042)$

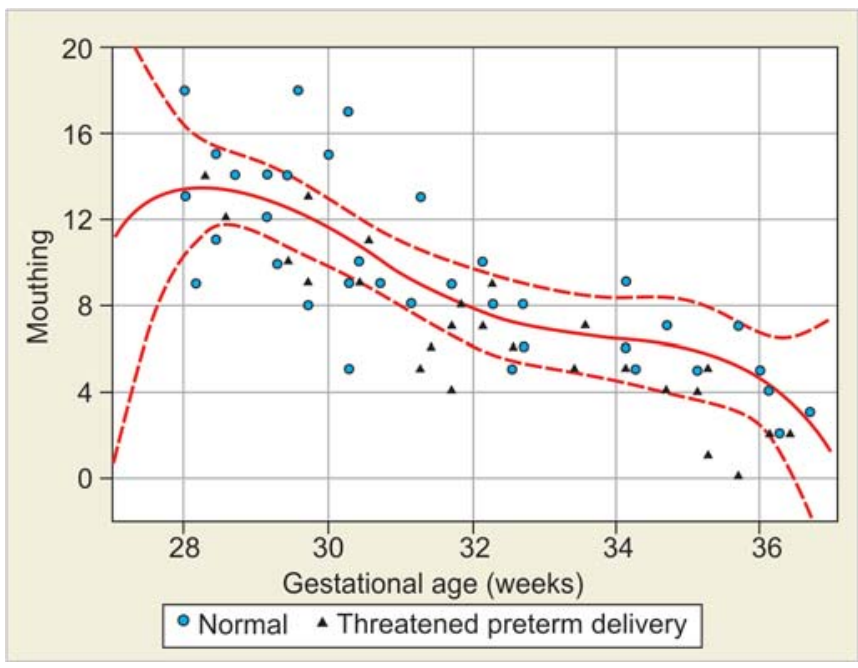

Fig. 17: Scatterplot and polynomial regression of the frequency of mouthing

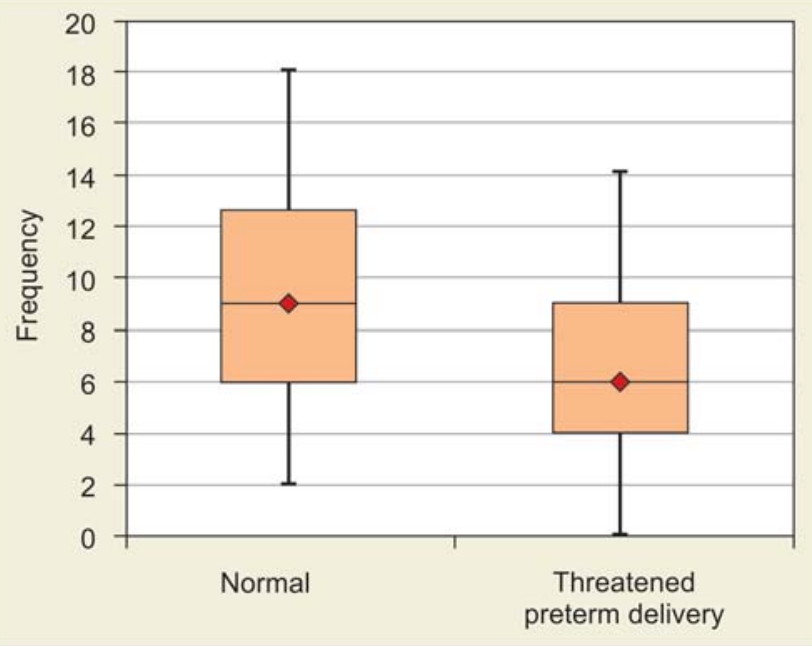

Fig. 18: Comparison of the frequency of mouthing between normal and threatened preterm delivery $(p=0.012)$

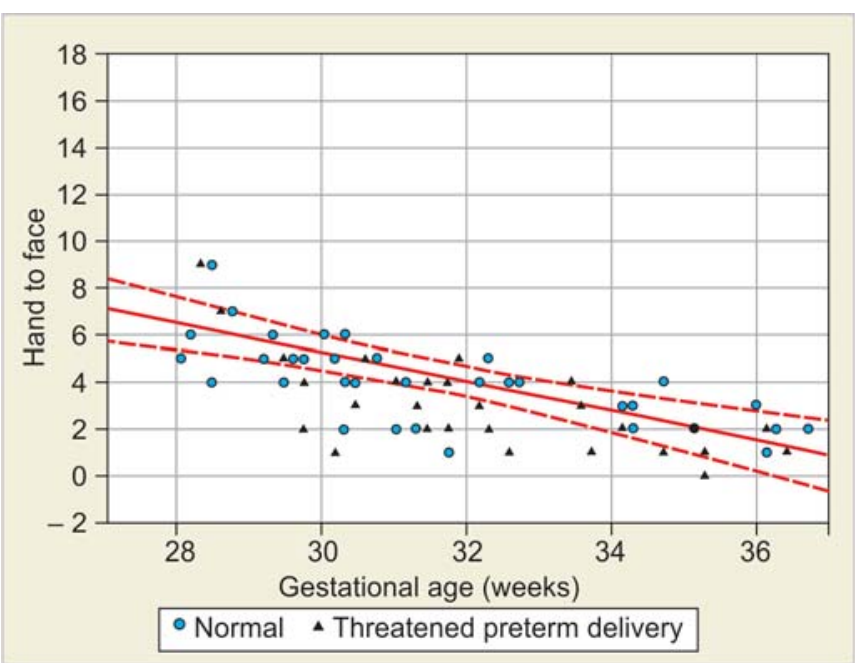

Fig. 19: Scatterplot and linear regression of the frequency of hand to face

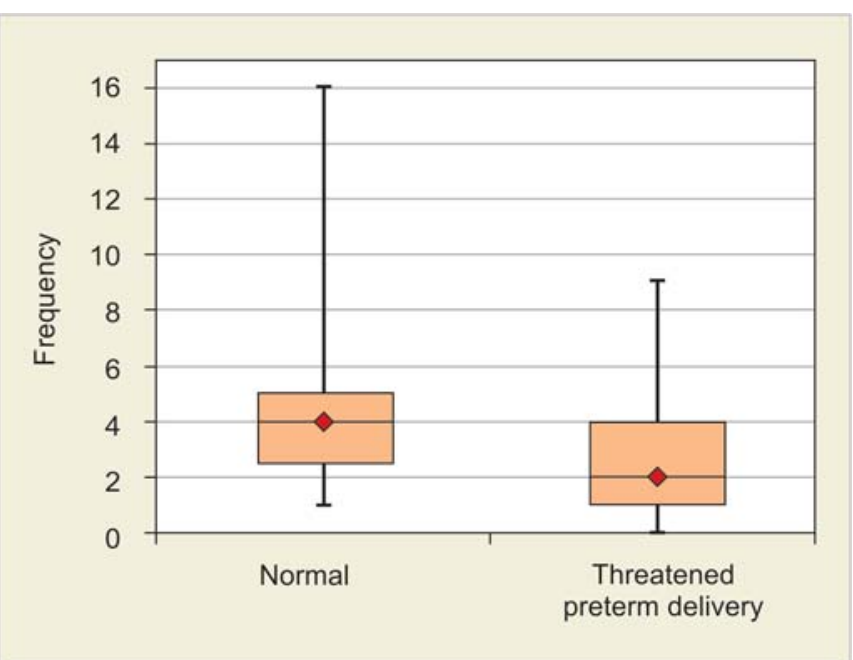

Fig. 20: Comparison of the frequency of hand to face between normal and threatened preterm delivery $(p=0.009)$ 


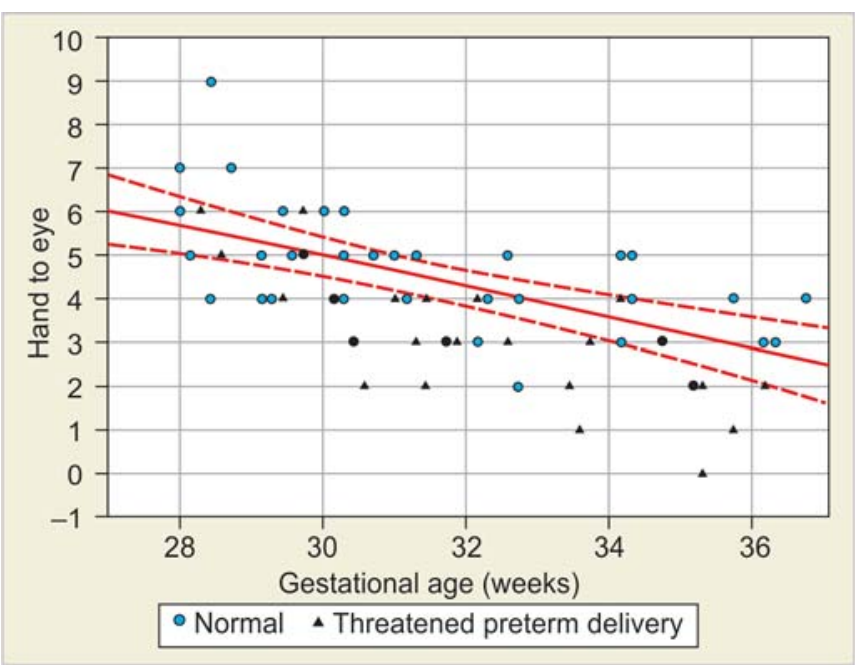

Fig. 21: Scatterplot and linear regression of the frequency of hand to eye

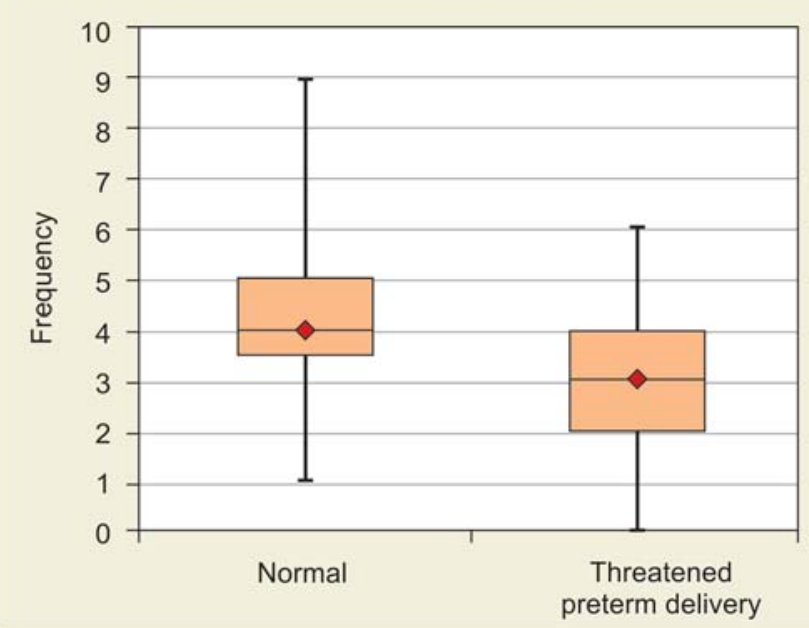

Fig. 22: Comparison of the frequency of hand to eye between normal and threatened preterm delivery $(p=0.003)$

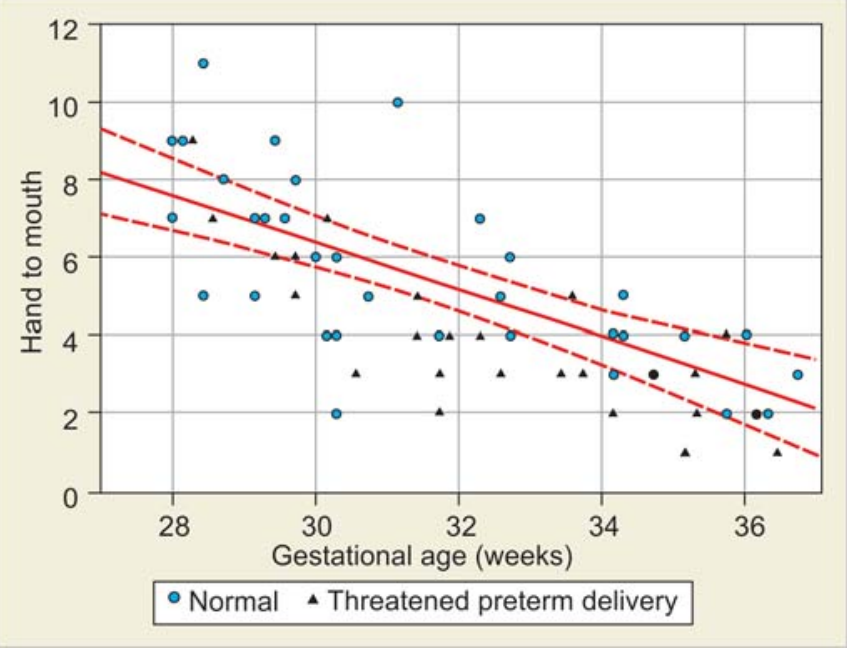

Fig. 23: Scatterplot and linear regression of the frequency of hand to mouth

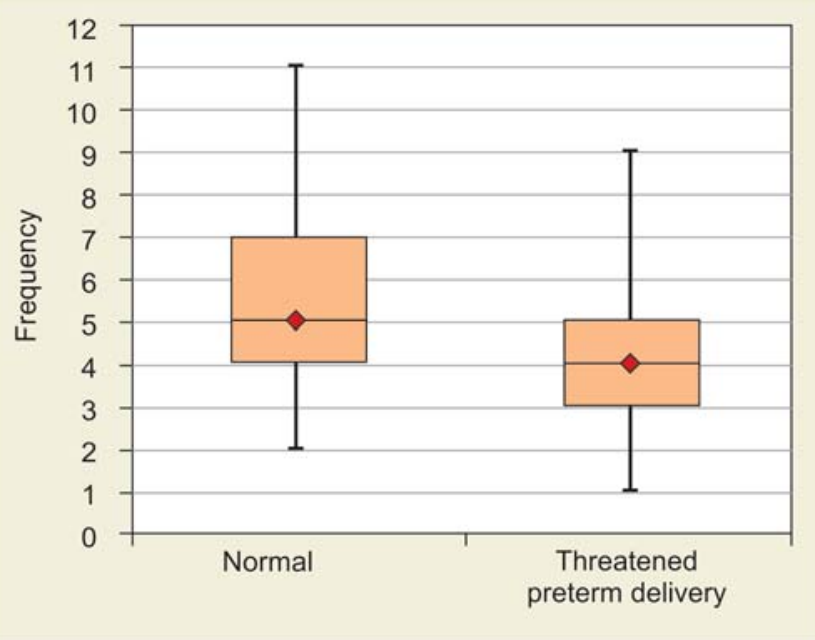

Fig. 24: Comparison of the frequency of hand to mouth between normal and threatened preterm delivery $(p=0.015)$

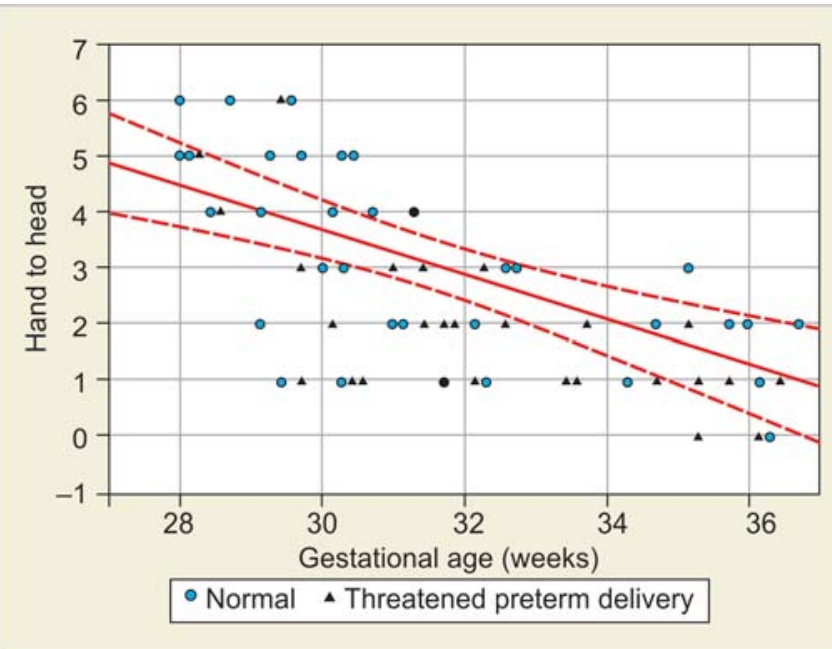

Fig. 25: Scatterplot and linear regression of the frequency of hand to head

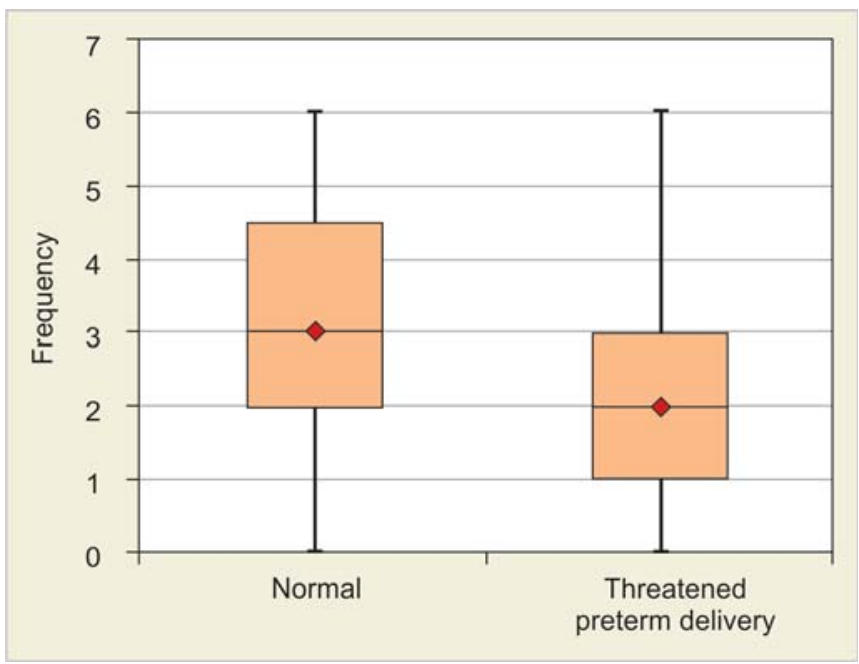

Fig. 26: Comparison of the frequency of hand to head between normal and threatened preterm delivery $(p=0.007)$ 


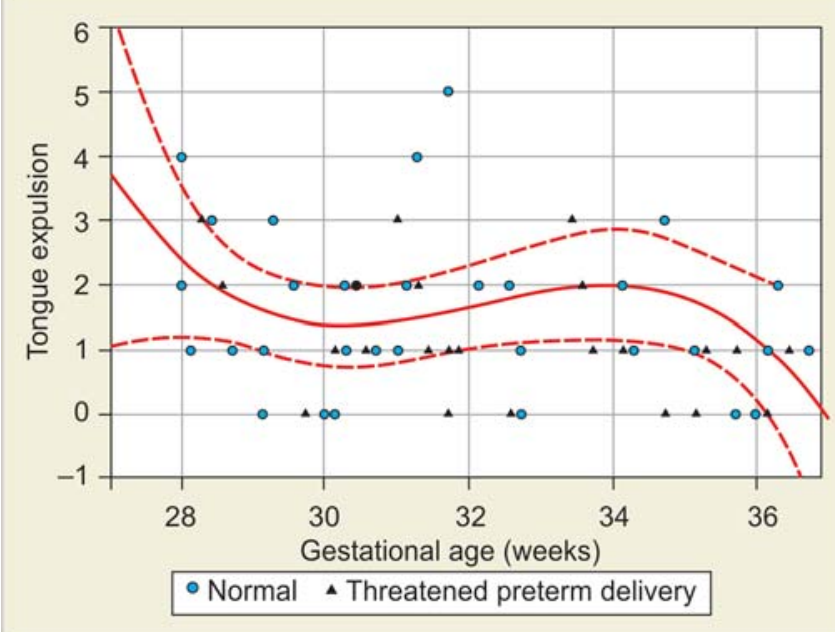

Fig. 27: Scatterplot and polynomial regression of the frequency of tongue expulsion

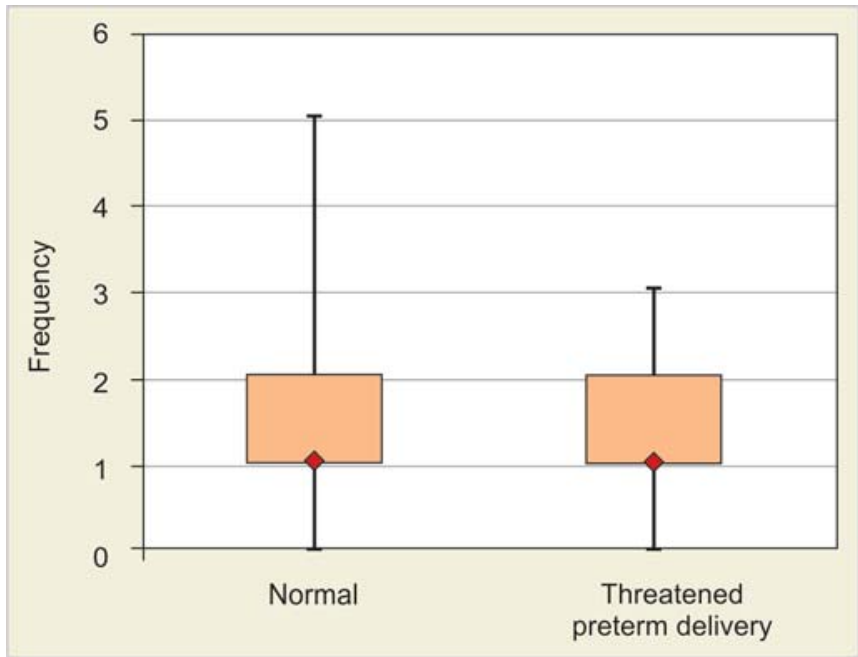

Fig. 28: Comparison of the frequency of tongue expulsion between normal and threatened preterm delivery $(p=0.133)$

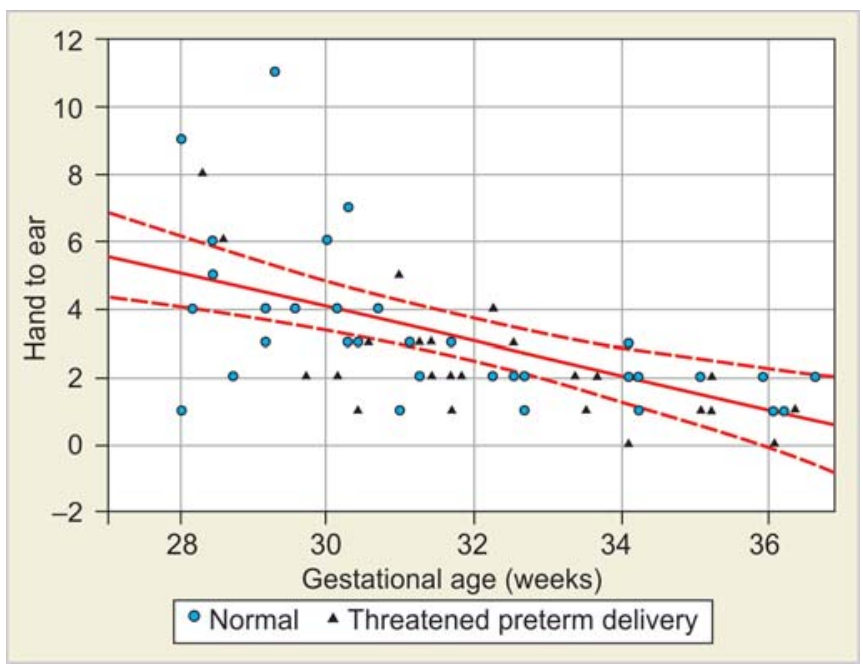

Fig. 29: Scatterplot and linear regression of the frequency of hand to ear

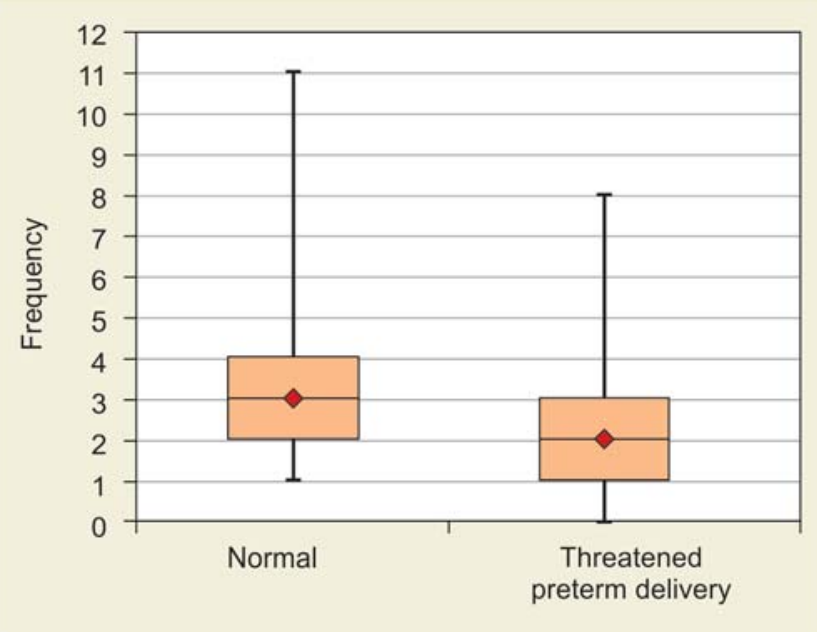

Fig. 30: Comparison of the frequency of hand to ear between normal and threatened preterm delivery $(p=0.086)$

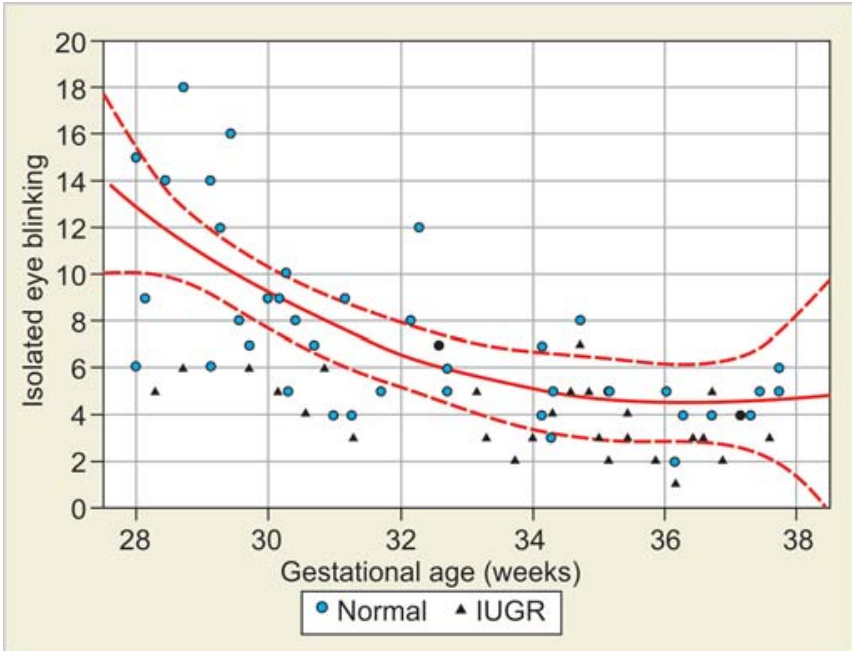

Fig. 31: Scatterplot and polynomial regression of the frequency of isolated eye blinking

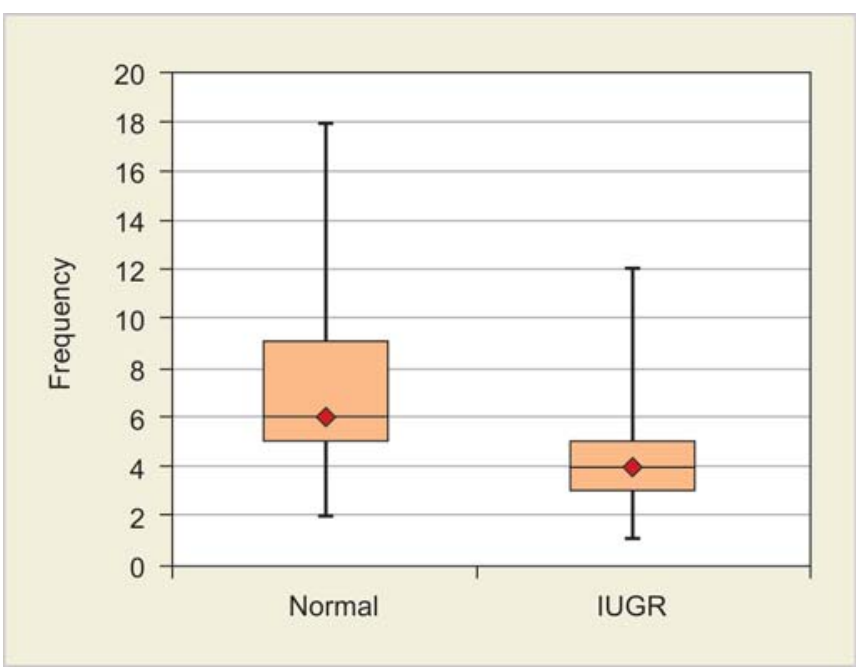

Fig. 32: Comparison of the frequency of isolated eye blinking between normal and IUGR $(p<0.001)$ 


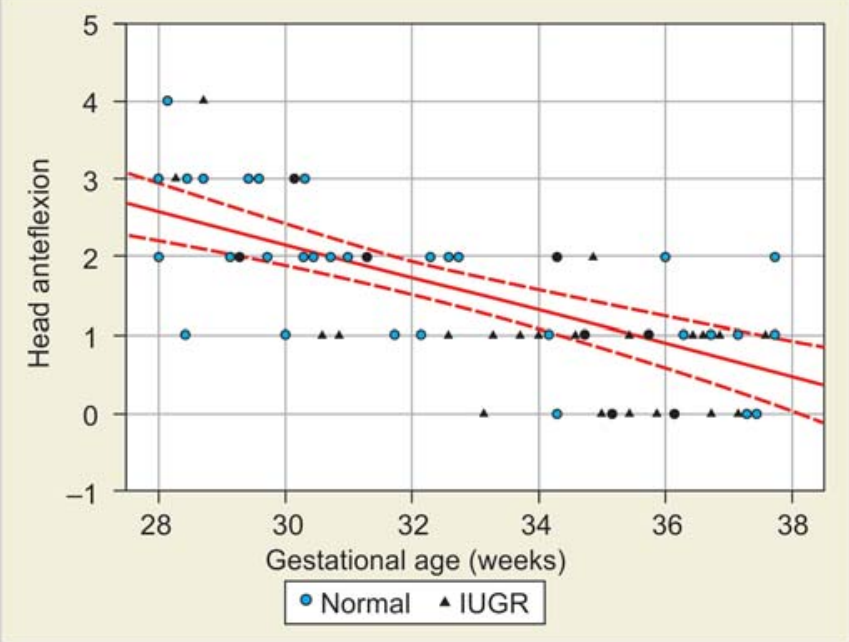

Fig. 33: Scatterplot and linear regression of the frequency of head anteflexion

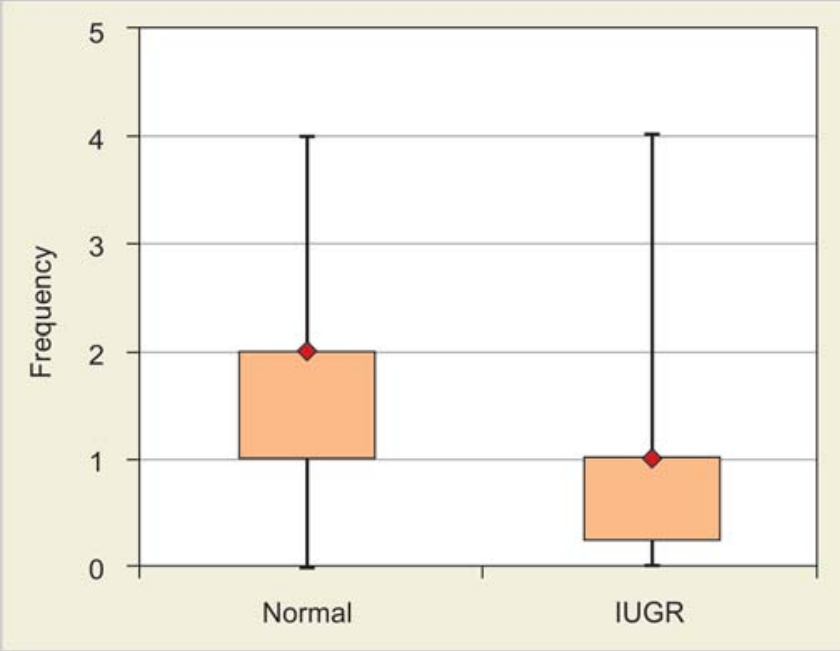

Fig. 34: Comparison of the frequency of head anteflexion between normal and IUGR $(p=0.006)$

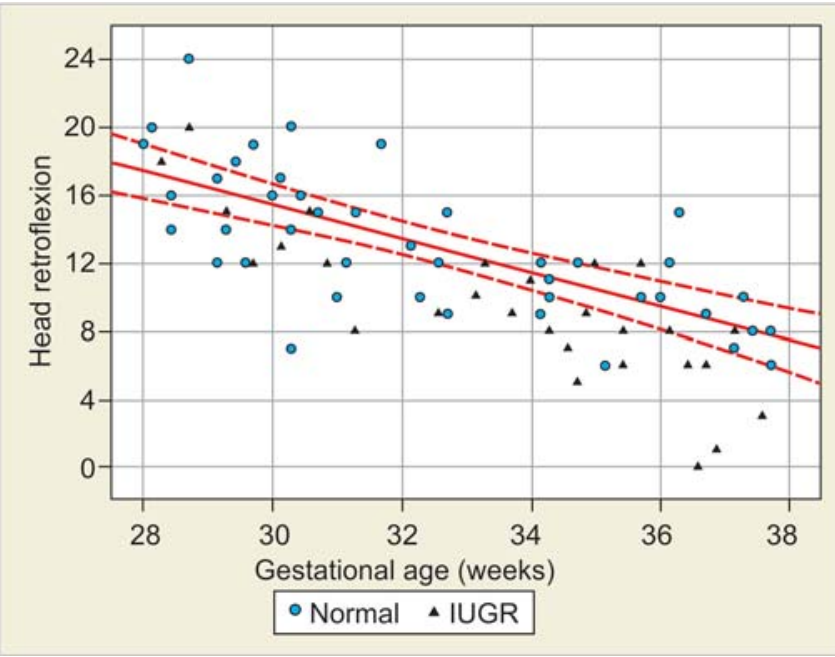

Fig. 35: Scatterplot and linear regression of the frequency of head retroflexion

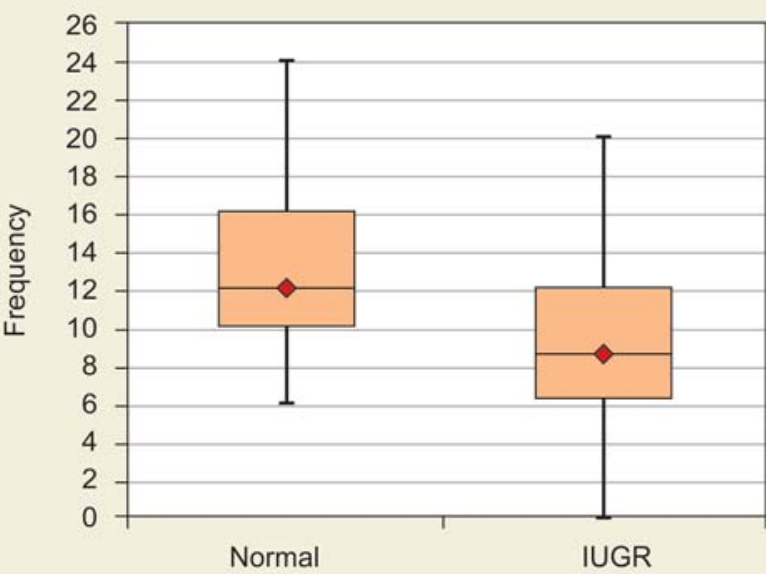

Fig. 36: Comparison of the frequency of head retroflexion between normal and IUGR threatened $(p<0.001)$

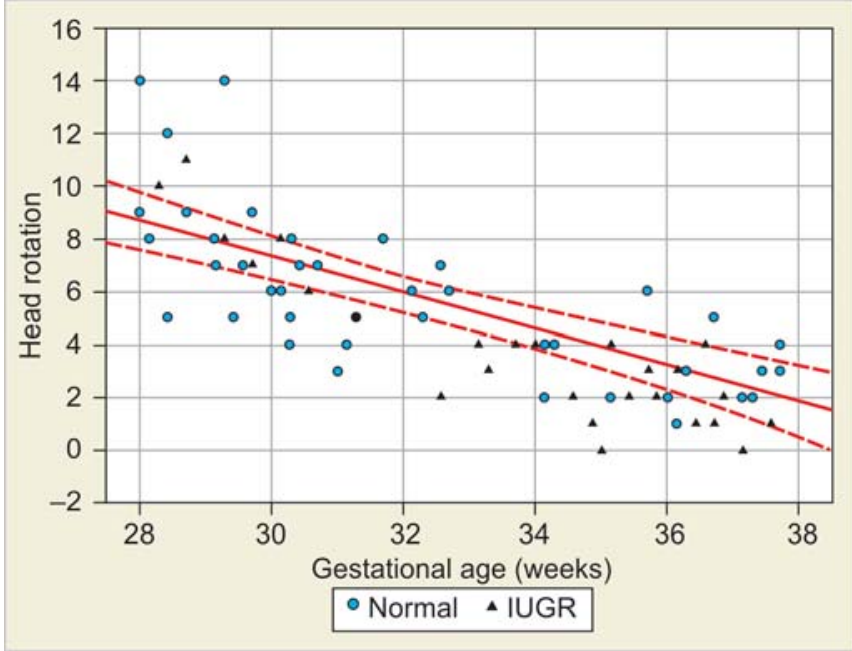

Fig. 37: Scatterplot and linear regression of the frequency of head rotation

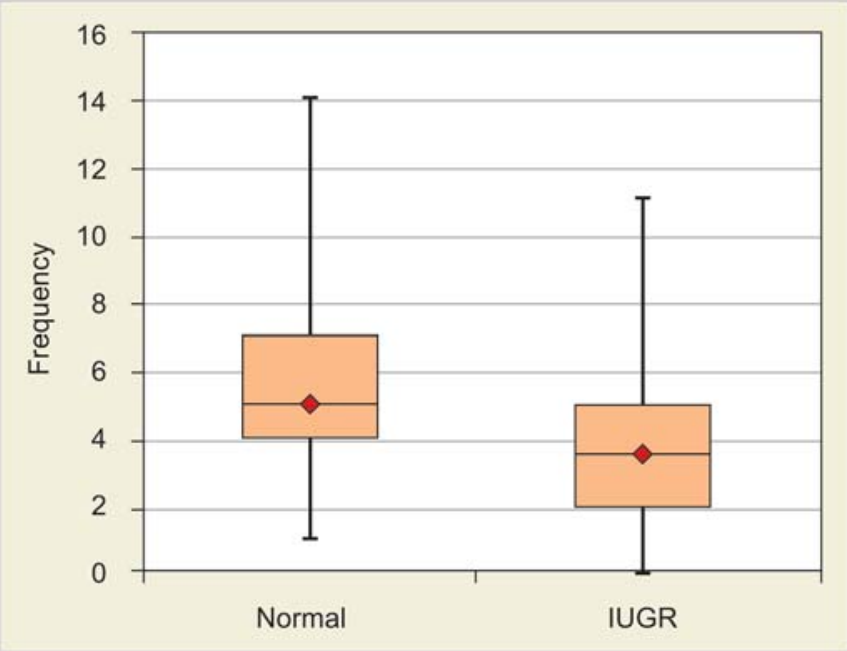

Fig. 38: Comparison of the frequency of head rotation between normal and IUGR threatened $(p=0.003)$ 


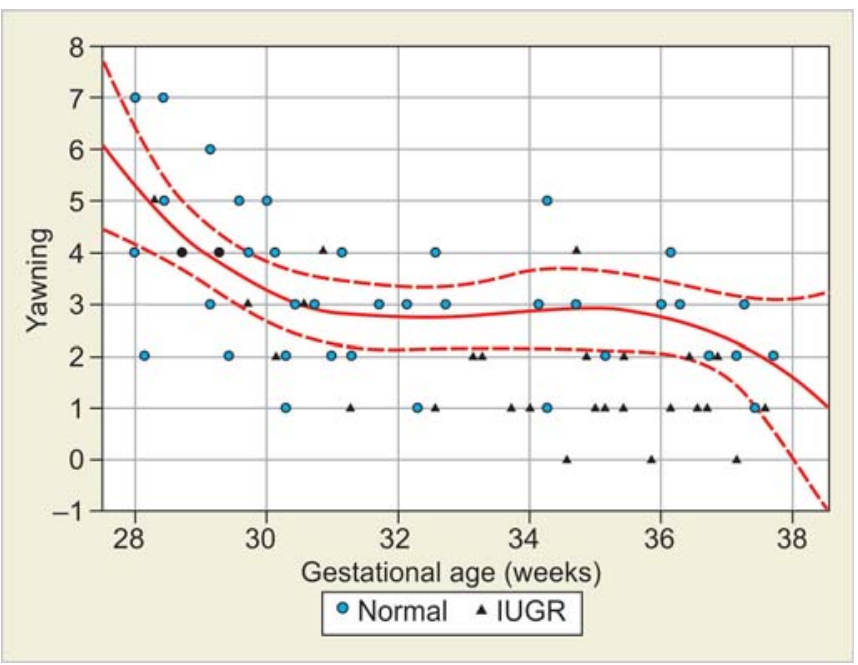

Fig. 39: Scatterplot and polynomial regression of the frequency of yawning

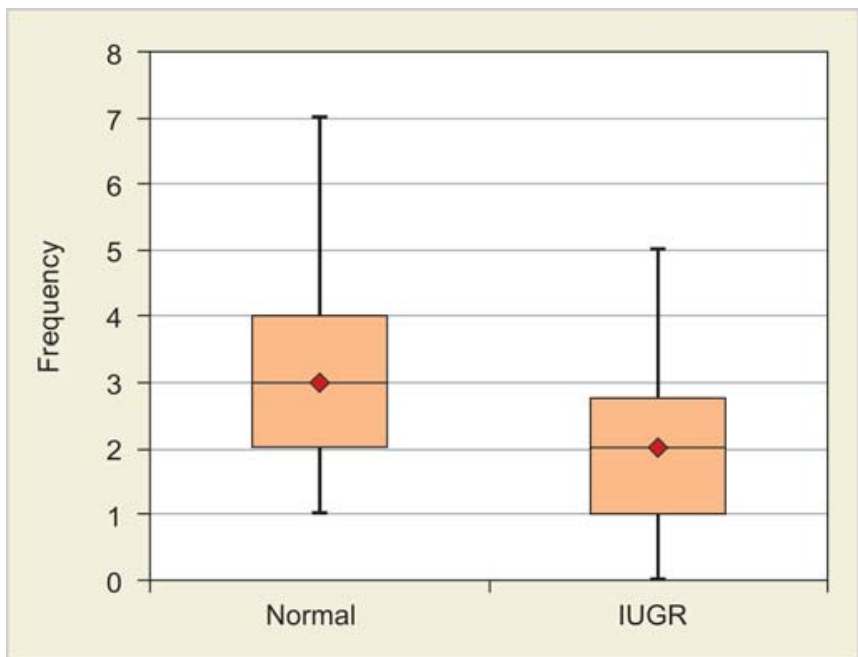

Fig. 40: Comparison of the frequency of yawning between normal and IUGR $(p<0.001)$

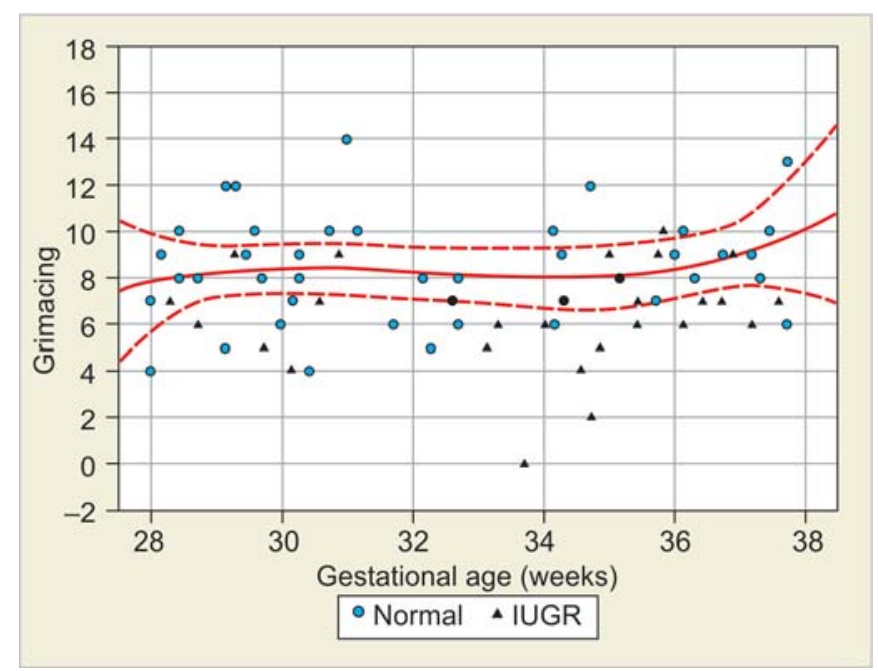

Fig. 41: Scatterplot and polynomial regression of the frequency of grimacing

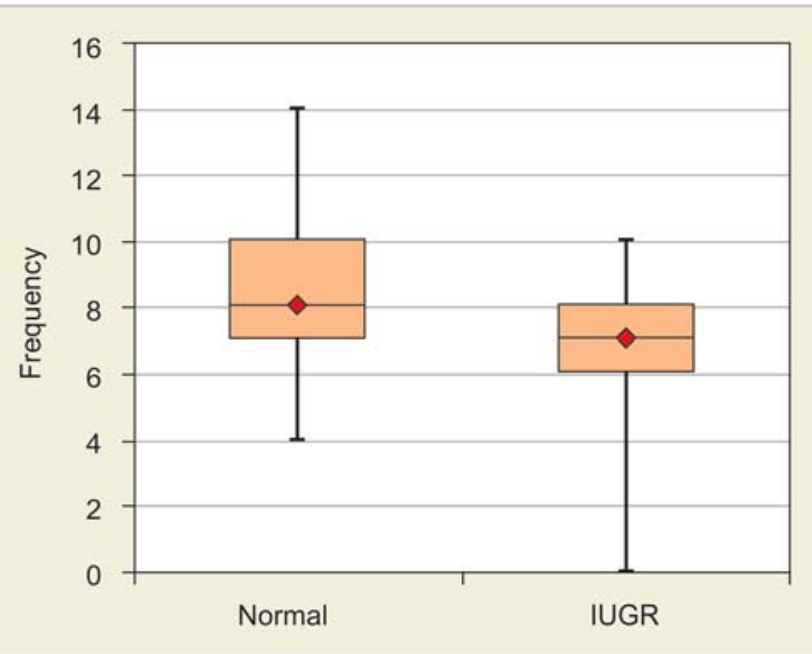

Fig. 42: Comparison of the frequency of grimacing between normal and IUGR $(p=0.001)$

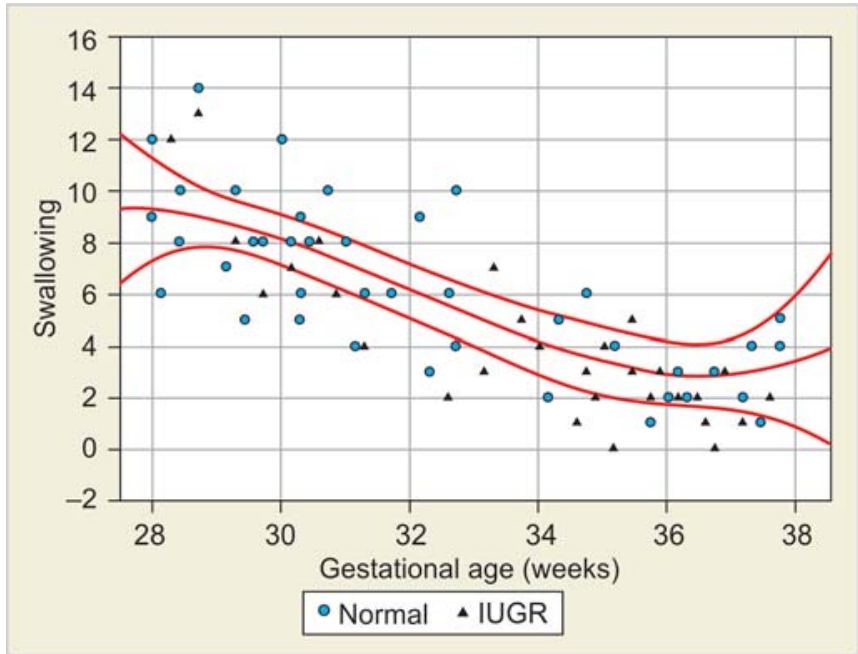

Fig. 43: Scatterplot and polynomial regression of the frequency of swallowing

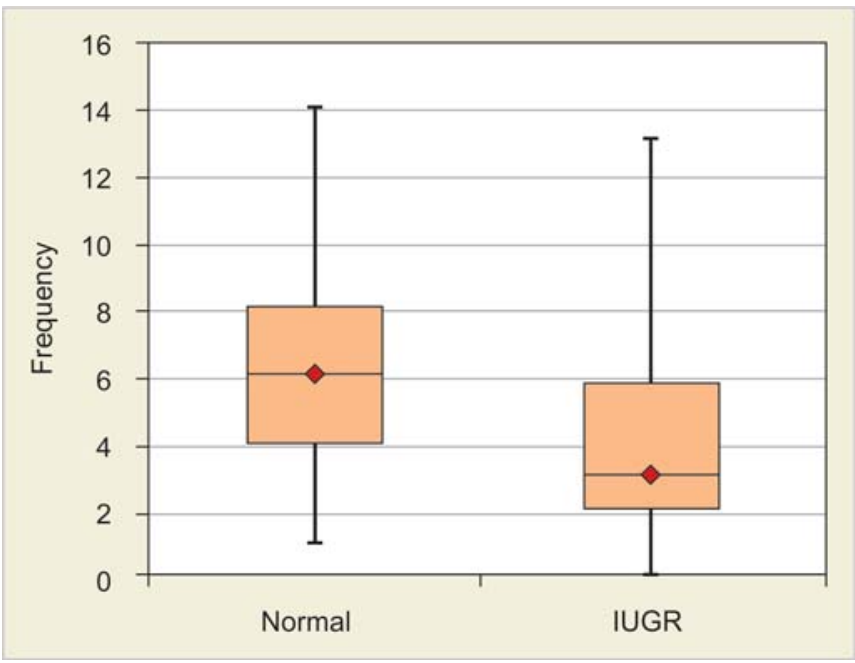

Fig. 44: Comparison of the frequency of swallowing between normal and IUGR $(p=0.004)$ 


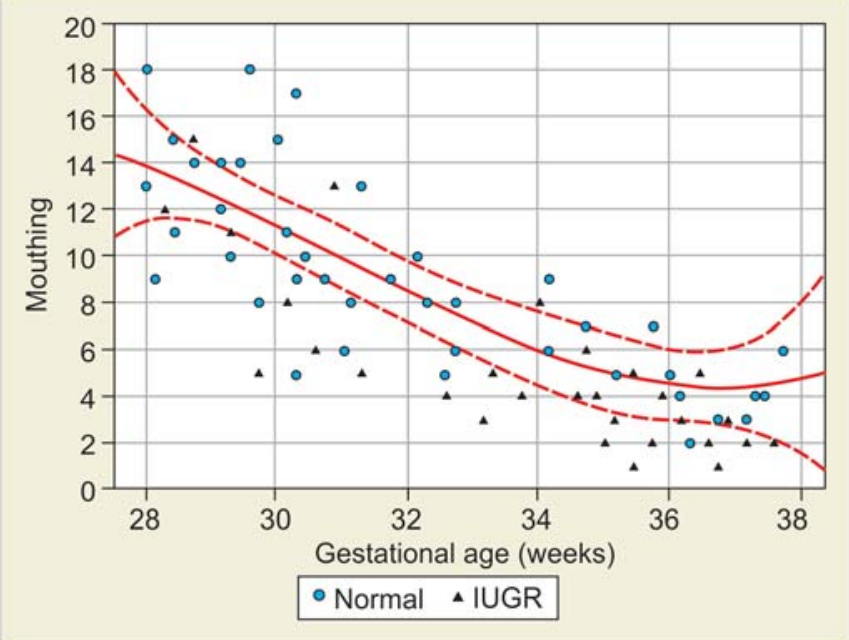

Fig. 45: Scatterplot and polynomial regression of the frequency of mouthing

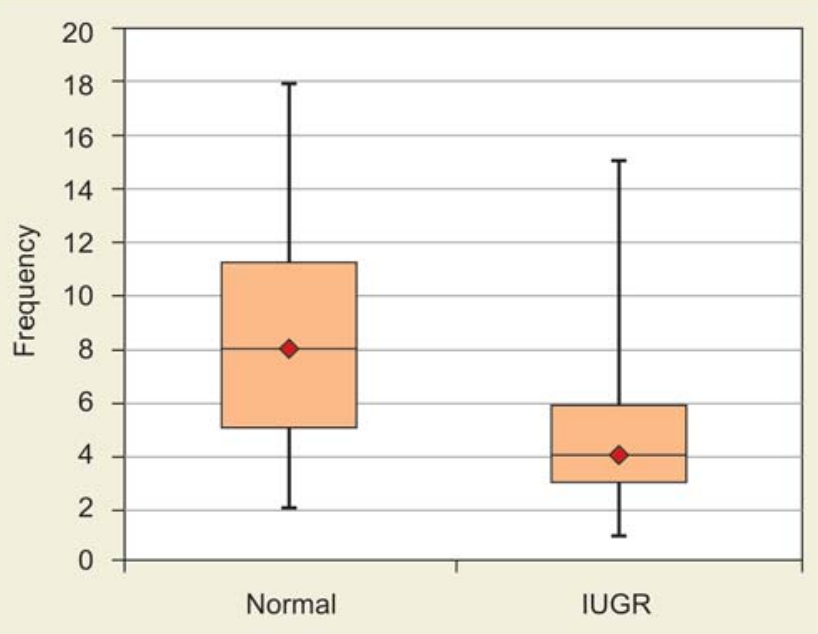

Fig. 46: Comparison of the frequency of mouthing between normal and IUGR $(p<0.001)$

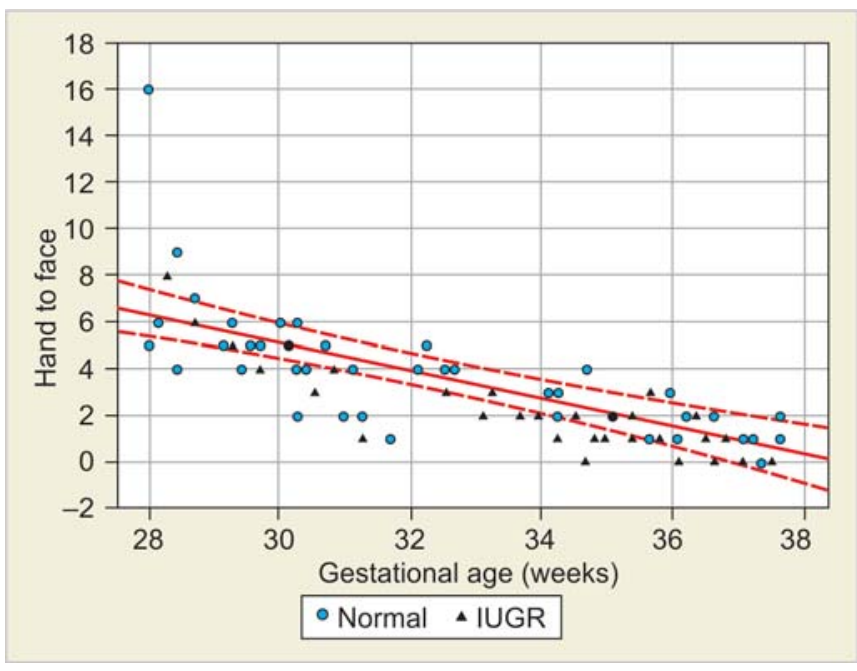

Fig. 47: Scatterplot and linear regression of the frequency of hand to face

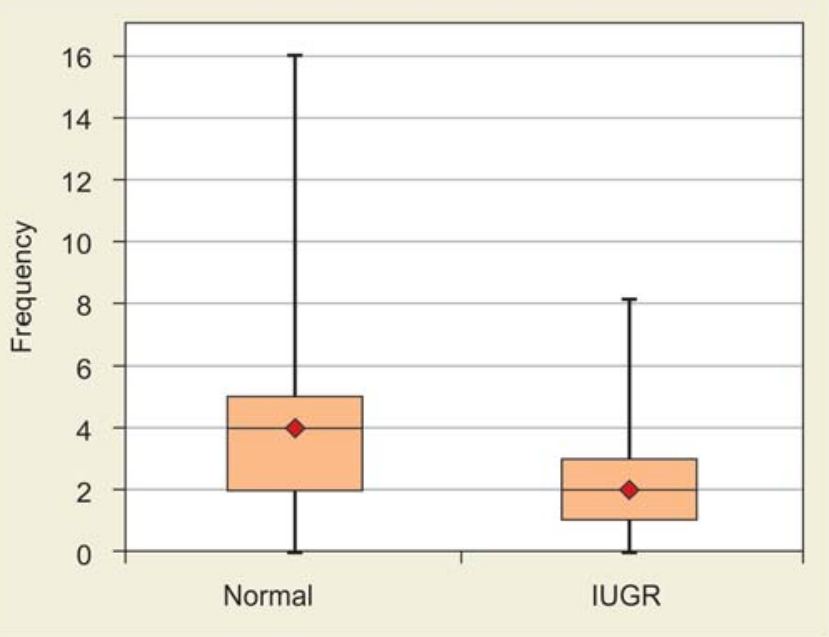

Fig. 48: Comparison of the frequency of hand to face between normal and IUGR $(p=0.001)$

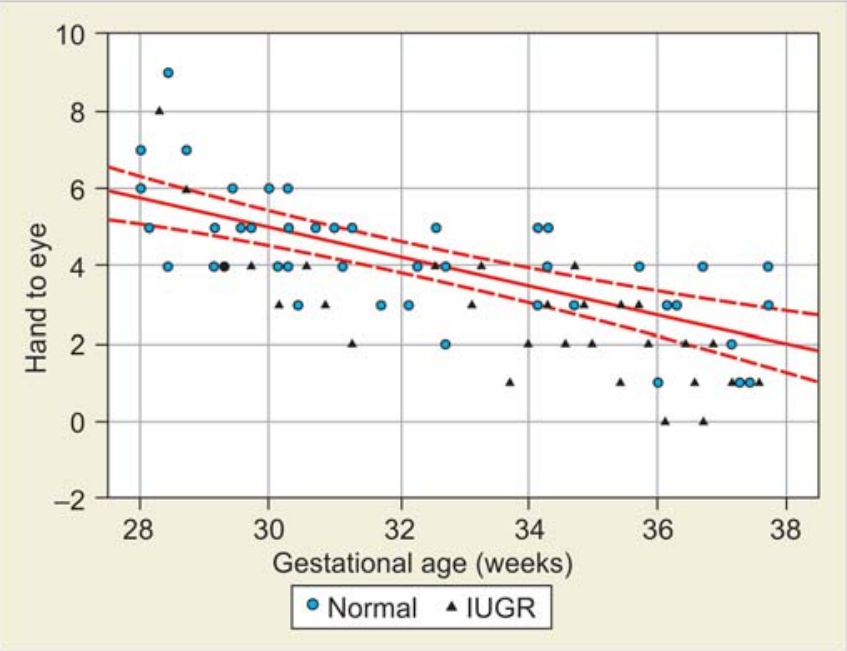

Fig. 49: Scatterplot and linear regression of the frequency of hand to eye

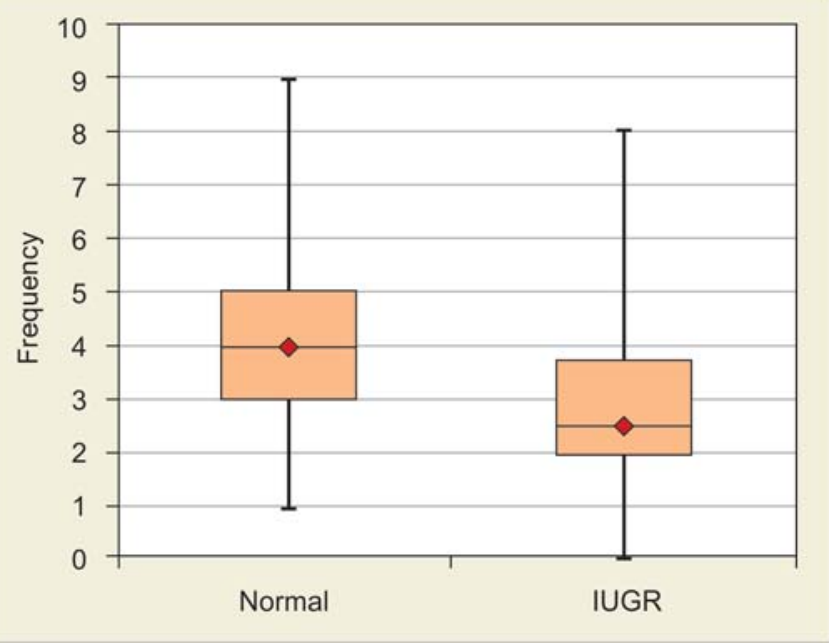

Fig. 50: Comparison of the frequency of hand to eye between normal and IUGR $(p<0.001)$ 


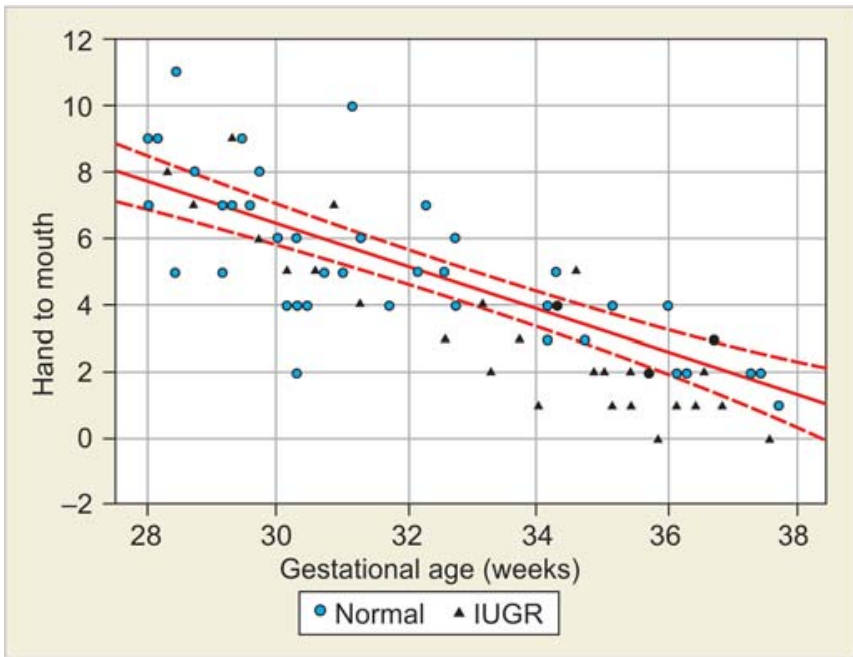

Fig. 51: Scatterplot and linear regression of the frequency of hand to mouth

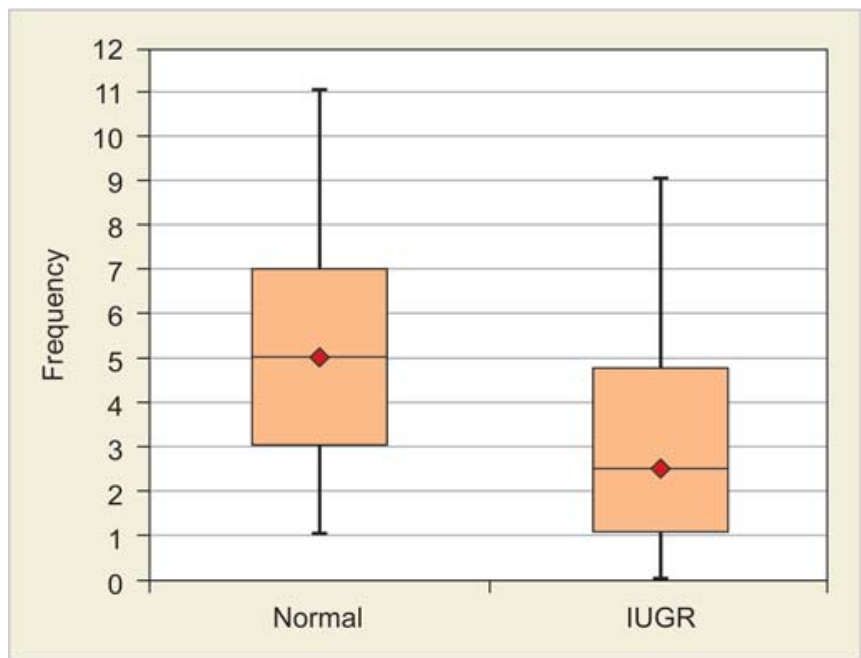

Fig. 52: Comparison of the frequency of hand to mouth between normal and IUGR $(p=0.003)$

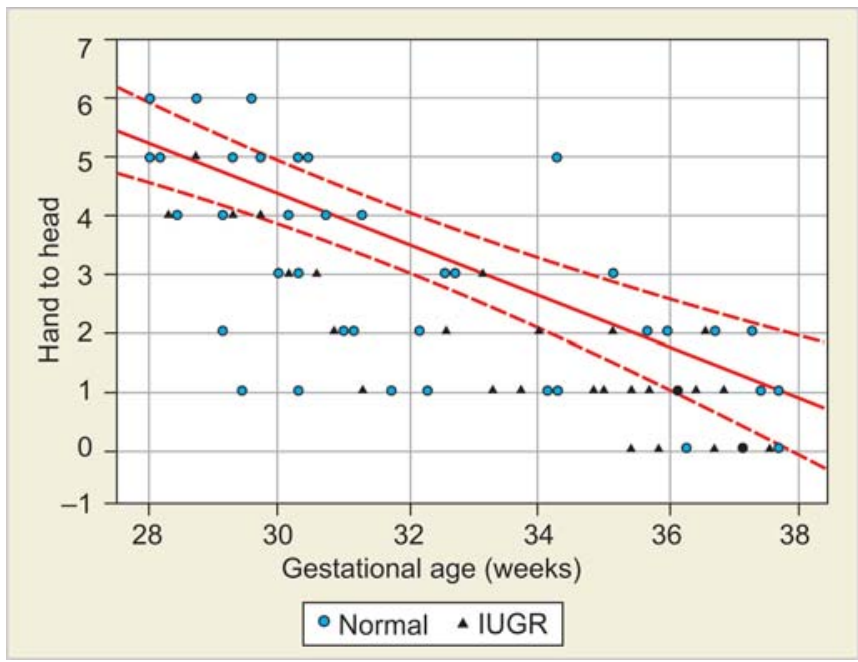

Fig. 53: Scatterplot and linear regression of the frequency of hand to head

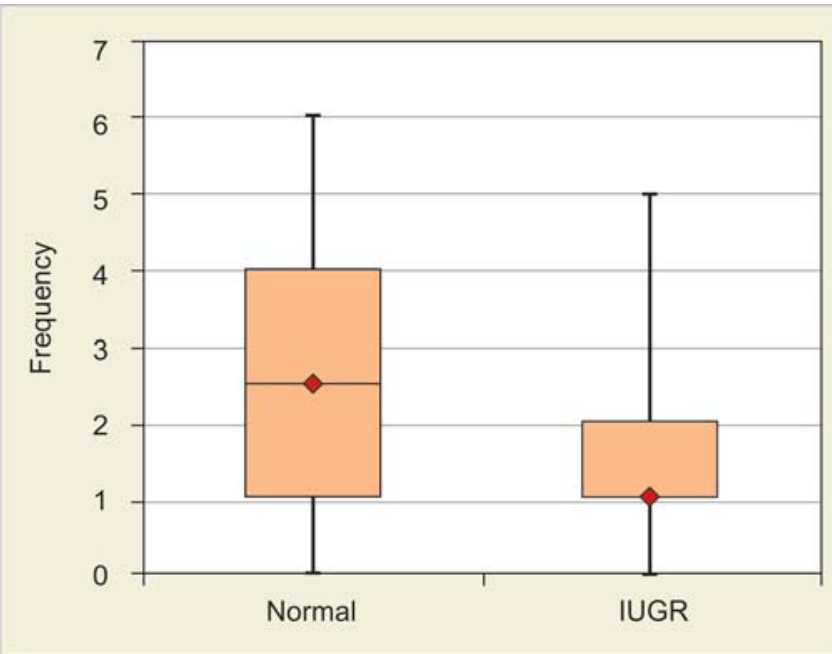

Fig. 54: Comparison of the frequency of hand to head between normal and IUGR $(p=0.008)$

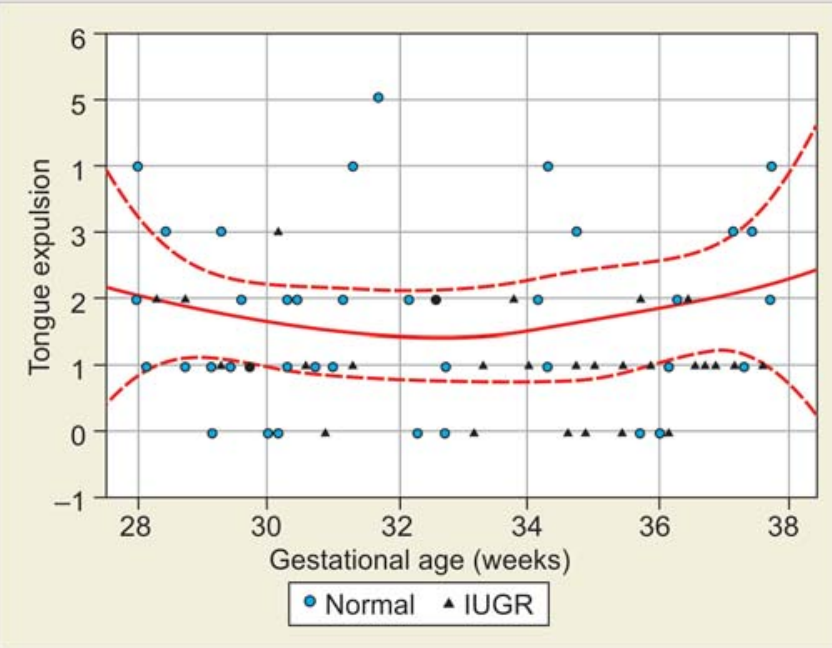

Fig. 55: Scatterplot and polynomial regression of the frequency of tongue expulsion

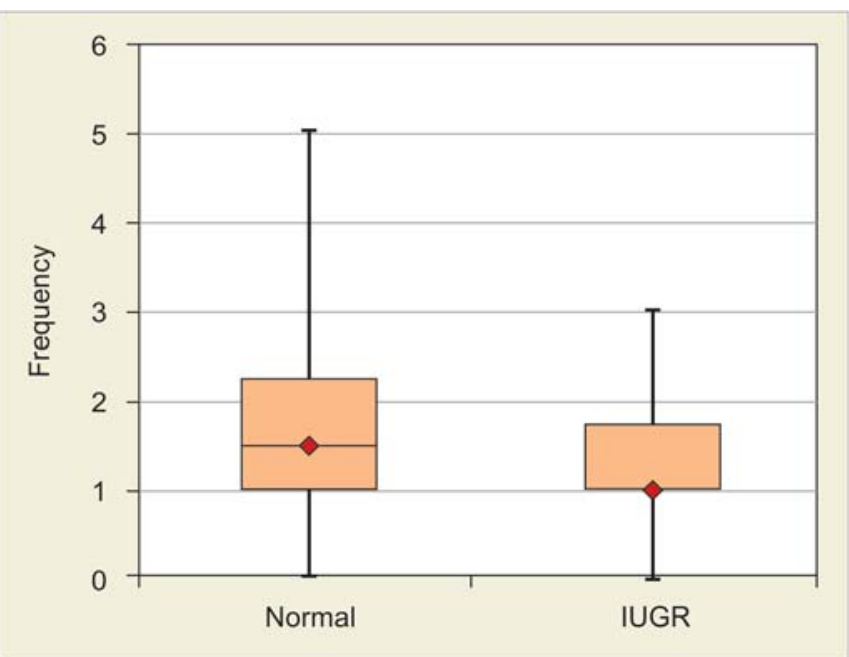

Fig. 56: Comparison of the frequency of tongue expulsion between normal and IUGR $(p=0.039)$ 


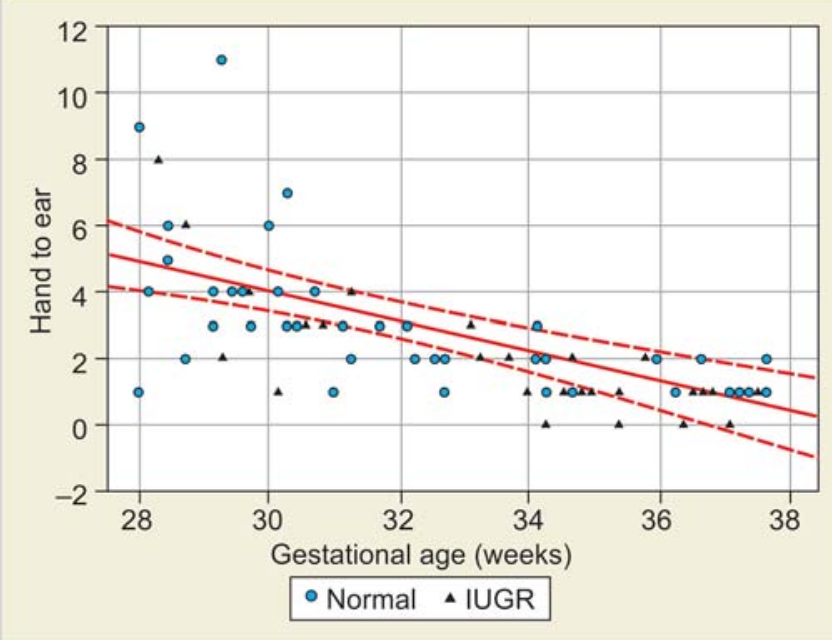

Fig. 57: Scatterplot and linear regression of the frequency of hand to ear

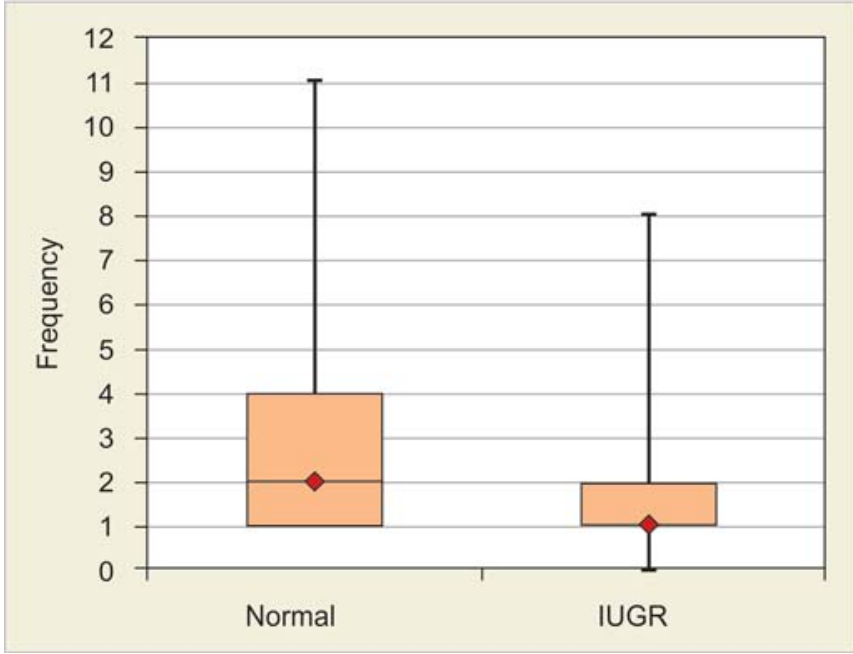

Fig. 58: Comparison of the frequency of hand to ear between normal and IUGR $(p=0.008)$

We found a tendency for threatened preterm delivery fetuses and fetuses came from pregnancies complicated by IUGR to have less behavioral activity than normal fetuses in all of the observed movement patterns.

\section{DISCUSSION}

During this study, we found significant differences in fetal movements in the two groups. In normal pregnancies, most fetuses (93.4\%) achieved a normal KANET score compared to $78.5 \%$ of the fetuses from high-risk pregnancies. Borderline and abnormal scores percentages became dominant in high-risk pregnancies.

In the high-risk pregnancy group, most abnormal KANET scores were in pregnancies complicated by threatened preterm delivery with PPROM (25\%). Most fetuses from pregnancies complicated by intrauterine growth restriction with MCA RI changes and by hypertension above
160/100 mm Hg achieved borderline score (50\%). We found the highest percentage of normal fetal movements in pregnancies complicated by $\mathrm{Rh}$ isoimmunization without hydrops fetalis (96\%).

In this study, the characteristics of reduced speed and amplitude were found in the threatened preterm delivery group. There was a reduction of both number and duration of general movements in the IUGR group. The growth restricted (IUGR) fetuses moved less and their general movements were poorly organized. Alterations in the quality of fetal movements were accompanied by considerable decreases in the quantity of fetal movements.

\section{CONCLUSION}

The major problem is that the study of fetal behavior takes time and has not yet been in routine ultrasound. Subjectivity of the examination by ultrasound can be corrected by records.

Behavior is closely related to fetal development and maturation processes of the central nervous system. Widespread assessment of the fetal movements can diagnose early many neurological diseases that have their origins more in peri- and postnatal periods than during intrauterine period.

The ultrasound assessment of fetal behavior could be used for detection of functional and structural brain disorders. ${ }^{12,27}$ Detection of abnormal fetal behavior requires postnatal neurological development monitoring for two years.

The KANET test could be proposed as a screening test to identify fetuses with risk of developing postpartum neurological dysfunction, the most serious of which being cerebral palsy.

\section{REFERENCES}

1. Kurjak A, Pooh R, Tikvica A, Stanojevic M, Miskovic B, Ahmed B, Azumendi G. Fetal Neurology (1st ed), 2009;7: 225-50;273-80.

2. Amiel-Tison C, Gosselin J, Kurjak A. Neurosonography in the second half of fetal life: A neonatologist's point of view. J Perinat Med 2006;34:437-46.

3. Salihagic-Kadic A, Medic M, Kurjak A, Andonotopo W, Azumendi G, Hafner T, Milenkovic D. 4D sonography in the assessment of fetal functional neurodevelopment and behavioural paterns. The Ultrasound Review of Obstetric and Gynecology 2005;5(2):1-15.

4. de Vries JI, Fong BF. Normal fetal motility: An overview. Ultrasound Obstet Gynecol 2006;27:701-11.

5. Lüchinger $A B$, Hadders-Algra $M$, van Kan CM, de Vries JI. Fetal onset of general movements. Pediatr Res 2008;63: 191-95.

6. Maeda K. Quantitative studies on fetal actocardiogram. Croat Med J 2005;46:792-96. 
7. Prechtl HFR. Qualitative changes of spontaneous movements in fetus and preterm infant are a marker of neurological dysfunction. Early Hum Dev 1990;23:151-58.

8. de Vries JI, Fong BF. Changes in fetal motility as a result of congenital disorders: An overview. Ultrasound Obstet Gynecol 2007;29:590-99.

9. Kurjak A, Miskovic B, Stanojevic M, Amiel-Tison C, Ahmed B, Azumendi G, Vasilj O, et al. New scoring system for fetal neurobehavior assessed by three- and four-dimensional sonography. J Perinat Med 2008;36:73-81.

10. Kurjak A, Vecek N, Hafner T, Bozek T, Funduk-Kurjak B, Ujevic B. Prenatal diagnosis: What does four-dimensional ultrasound add? J Perinat Med 2002;30:57-62.

11. Kurjak A, Azumendi G, Vecek N, Kupesic S, Solak M, Varga $\mathrm{D}$, et al. Fetal hand movements and facial expression in normal pregnancy studied by four-dimensional sonography. J Perinat Med 2003;31:496-508.

12. Stanojevic M, Talic A, Miskovic B, Vasilj O, Shaddad AN, Ahmed B, et al. An attempt to standardize Kurjak's antenatal neurodevelopmental test: Osaka Consensus Statement.DSJUOG 10.5005/jp-journals-10009-1209.

13. Kurjak A, Chervenak FA. Textbook of Perinatal Medicine (2nd ed), (Hardcover) 25 Sep, 2006:568-75.

14. Kurjak A, Stanojevic M, Azumendi G, Carrera JM. The potential of four-dimensional ultrasonography in the assessment of fetal awareness. J Perinat Med 2005;33:46-53.

15. Salihagic-Kadic A, Medic M, Kurjak A, Andonotopo W, Azumendi G, Hafner T, Milenkovic D. Four-dimensional sonography in the assessment of fetal functional neurodevelopment and behavioral patterns. Ultrasound Rev Obstet Gynecol 2005;5:154-68.

16. Kurjak A, Carrera J, Medic M, Azumendi G, Andonotopo W, Stanojevic M. The antenatal development of fetal behavioral patterns assessed by four-dimensional sonography. J Matern Fetal Neonatal Med 2005;17:401-16.

17. Kurjak A, Andonotopo W, Stanojevic M, Milenkovic D, Azumendi G, Hafner T, Ujevic B. Longitudinal study of fetal behavior by 4D sonography: The ultrasound review of obstetric and gynecology. 2005;00(0):1-16.

18. Rennie JM, Hagmann CF, Robertson NJ. Outcome after intrapartum hypoxic ischaemia at term. Semin Fetal Neonatal Med 2007;12:398-407.

19. O'Shea TM. Diagnosis, treatment, and prevention of cerebral palsy. Clin Obstet Gynecol 2008;51:816-28.

20. Longo M, Hankins GD. Defining cerebral palsy: Pathogenesis, pathophysiology and new intervention. Minerva Ginecol 2009;61:421-29.
21. Graca LM, Cardoso CG, Clode N, et al. Acute effects of maternal cigarette smoking on fetal heart rate and fetal movements felt the mother. J Perinat Med 1991;19:385-90.

22. Katz M, Meizner I, G. Holcberg, M. Mazor M, et al. Reduction or cessation of fetal movements after administration of steroids for enhancement of lung maturation. Israel J Med Science 1988;24:5-9.

23. Visser GH, Mulder EJ, Tessa Ververs FF. Fetal behavioral teratology. J Matern Fetal Neonatal Med 2010;23(Suppl 3): 14-16.

24. Salihagic-Kadic A, Medic M, Kurjak A. Neurophysiology of fetal behavior. The Ultrasound Review of Obstetric and Gynecology June 2004:1-12.

25. Araki M, Nishitani S, Ushimaru K, Masuzaki H, Oishi K, Shinohara K. Fetal response to induced maternal emotions. J Physiol Sci 2010;60:213-20.

26. Kurjak A, Carrera JM, Andonotopo W, Azumendi G, Medic MA. Salihagic-Kadic. Behavioral perinatology assessed by fourdimensional sonography. Textbook of Perinatal Medicine 2003;42:582-88.

27. Carrera JM, Kurjak A. Atlas of clinical applications of ultrasound in obstetrics and gynecology (Hardcover), 1 Aug., 2006.

28. Kurjak A, Abo-Yaqoub S, Stanojevic M, Yigiter AB, Vasilj O, Lebit $\mathrm{D}$, et al. The potential of $4 \mathrm{D}$ sonography in the assessment of fetal neurobehavior-multicentric study in high-risk pregnancies. J Perinat Med 2010;38:77-82.

\section{ABOUT THE AUTHORS}

\section{Radu Vladareanu}

Professor and Chairman, Department of Obstetrics and Gynecology Carol Davila University of Medicine, Elias University Hospital Bucharest, Romania

\section{Daniela Lebit}

Specialist, Department of Obstetrics and Gynecology, Elias University Hospital, Bucharest, Romania

\section{Simona Constantinescu}

Chief, Department of Neonatology, Elias University Hospital Bucharest, Romania

\section{CORRESPONDING AUTHOR}

Radu Vladareanu, Professor and Chairman, Department of Obstetrics and Gynecology, Carol Davila University of Medicine, Elias University Hospital, Marasti 17, Bucharest, Romania, Phone: +40.722.351.081 e-mail: vladareanu@gmail.com 